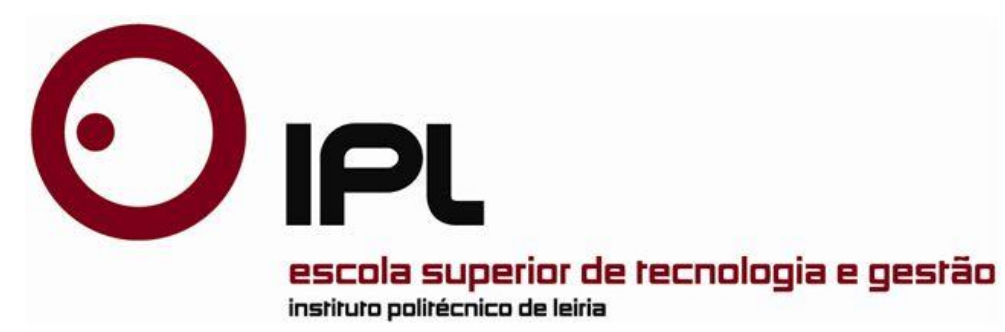

Dissertação

Mestrado em Gestão

\title{
Reciclagem com Incentivo Económico e a Heurística da Ancoragem
}

Joana Luísa Pinho Fernandes 



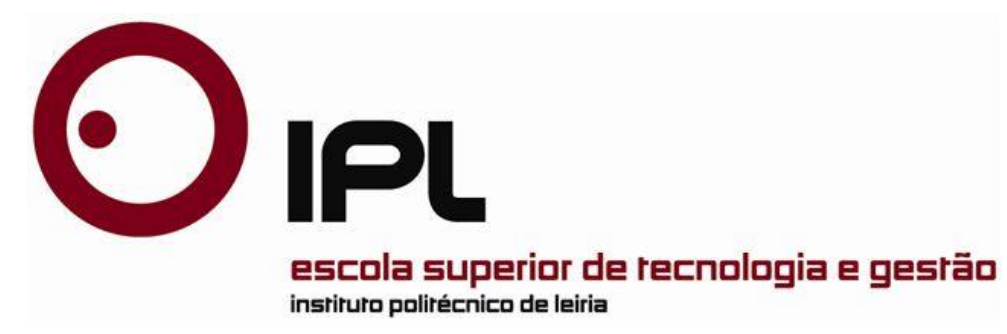

Dissertação

Mestrado em Gestão

\section{Reciclagem com Incentivo Económico e a Heurística da Ancoragem}

\section{Joana Luísa Pinho Fernandes}

Dissertação de Mestrado realizada sob a orientação da Doutora Maria Eduarda da Silva Teixeira Fernandes, Professora Adjunta da Escola Superior de Tecnologia e Gestão do Instituto Politécnico de Leiria. 
Esta página foi intencionalmente deixada em branco 


\section{Dedicatória}

Aos meus pais, Graça e Carlos. 
Esta página foi intencionalmente deixada em branco 


\section{Agradecimentos}

Disse José de Alencar "O poder nasce do querer. Sempre que o homem aplicar a veemência e perseverante energia da sua alma a um fim, vencerá os obstáculos, e, se não atingir o alvo fará, pelo menos, coisas admiráveis". Neste caminho não estive só e é por isso que agradeço, em primeiro lugar aos meus pais, Graça e Carlos por me ensinarem lutar pelos sonhos mesmo quando mais ninguém acreditar. Por me mostrarem que a nossa coragem, garra e luta pode vencer tudo, até prognósticos médicos traçados.

À Doutora Eduarda Fernandes, autora do tema, para a qual não consigo ter palavras para agradecer toda a ajuda, orientação, as palavras nos momentos mais difíceis, a ínfima paciência e compreensão. Trago-a genuinamente no meu coração.

Agradeço à Doutora Lígia Febra, orientadora do mestrado, por não me ter deixado desistir e pelo sorriso que sempre recebi.

À Doutora Alexandra Seco pelo apoio na parte estatística deste trabalho e à Técnica de Gestão do IPL, Sra. Tatiana Santos pela preciosa ajuda na construção dos questionários.

Às minhas irmãs, Ângela e Teresa agradeço a ajuda e a paciência.

Ao meu grande amigo André, pelas ínfimas horas de apoio que me deu e por todas as vezes que me lembrou que eu era capaz.

À Sandra, por me ter ouvido chorar a exaustão nos primeiros dias de aulas do mestrado conciliado com o trabalho e por toda a amizade e carinho.

À Patrícia, a minha parceira do mestrado, por todos os sorrisos que me despertou nos momentos de desânimo, pela amizade e pelo incrível empenho na distribuição de questionários.

Ao Jimmy, por todo o carinho, compreensão e força num dos momentos mais duros deste processo.

Aos que responderam aos questionários e a todos aqueles que se fizeram estar presentes, aos que compreenderam a minha ausência, aos que me ouviram desanimada e aos que festejaram comigo as minhas vitórias, aos que suportaram o meu mau humor e aos que me acarinharam sempre. Esta vitória não é apenas minha, é nossa! 
Esta página foi intencionalmente deixada em branco 


\section{Resumo}

O presente relatório foi realizado no âmbito do Mestrado em Gestão e teve como objetivo averiguar a existência de um efeito ancoragem no estabelecimento do valor de um incentivo económico para a reciclagem, utilizando-se para o efeito três questionários distintos, que pretendiam obter, junto dos inquiridos, os valores que os mesmos consideravam necessário que lhes fosse pago para que fizessem sempre a reciclagem no seu dia-a-dia.

Tendo em conta o atual debate nacional, em termos da necessidade de implementar instrumentos económicos associados à performance da gestão de resíduos (Assembleia da República, 2013), uma correta fixação do valor do incentivo assume particular importância.

O presente estudo analisou o impacto da utilização de uma âncora alta e uma âncora baixa para três tipos de materiais distintos: plástico, vidro e papel. Estas âncoras foram calculadas com base nas respostas dadas a um primeiro questionário, chamado questionário do grupo de calibragem.

No caso da âncora alta, o valor que as pessoas consideravam ser necessário receber para que reciclassem sempre, obteve um índice de ancoragem para o material vidro, que se destacou quando comparado com o mesmo índice em relação aos materiais, plástico e papel.

Naquilo que diz respeito à âncora baixa, os resultados foram bastante mais surpreendentes. Em destaque, esteve também o material vidro, ainda que os resultados relacionados com os materiais, plástico e papel, tenham sido também bastante claros.

Verificou-se que existe um efeito ancoragem inerente à tomada de decisão dos indivíduos quanto apontam o valor que consideram necessário para que façam sempre a reciclagem. Ou seja, o valor apontado pelos indivíduos, foi influenciado por valores apontados em questões anteriores.

Palavras-chave: ancoragem, incentivo económico, avaliação contingente e reciclagem. 
Esta página foi intencionalmente deixada em branco 


\section{Abstract}

This study was carried out under de Master in Management and aimed to verify the existence of an anchoring effect in the determination of an economic incentive for recycling, using for this purpose three different questionnaires, which sought to obtain from people inquired, the values that they would need to receive to always do recycling in their daily lives.

Considering the current discussion in Portugal about the need to implement economic instruments to improve waste management performance (Assembleia da República, 2013), the correct setting of the incentive value assumes a particular importance.

This study examined the impact of using a high and a low anchor for three distinct types of materials: plastic, glass and paper. These anchors were calculated based on responses to a first survey called the calibration group.

In the high anchor situation, the value that people needed to receive to always recycling got an anchor index to the material glass, which stood out when compared with the same index in relation to plastic and paper.

In what concerns the lower anchor, the results were much more striking. Highlighted, it was also the material glass, although the results related to the other materials, plastic and paper, have also been very clear.

It has been found that there is an anchor effect inherent to the individual decision making point as the value considered necessary to always make recycling. That is, the value pointed to by individuals it was influenced by the values used in the previous questions.

Keywords: anchoring, economic incentive, contingent valuation and recycling. 
Esta página foi intencionalmente deixada em branco 


\section{Lista de Gráficos}

Gráfico 1: Género dos Inquiridos....................................................................... 20

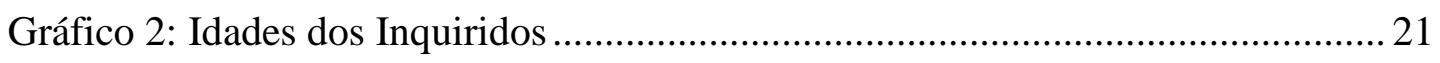

Gráfico 3: Habilitações académicas dos inquiridos ............................................... 21

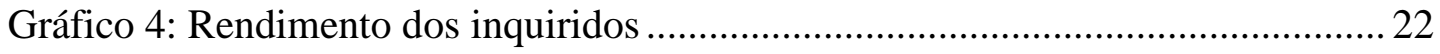

Gráfico 5: Hábito de separação dos lixos dos inquiridos ........................................ 23

Gráfico 6: Hábito de encher as máquinas de lavar antes de as colocar a funcionar .. 24

Gráfico 7: Hábito de compra de papel reciclado dos inquiridos ............................... 25

Gráfico 8: Hábito de reutilização de sacos de plástico dos inquiridos....................... 25

Gráfico 9: Utilização de lâmpadas de baixo consumo por parte dos inquiridos ........ 26

Gráfico 10: Hábito de compra de produtos com o rótulo ecológico dos inquiridos .. 27

Gráfico 11: Reciclagem com incentivo económico no caso do plástico.................... 29

Gráfico 12: Reciclagem com incentivo económico no caso do vidro......................... 30

Gráfico 13: Reciclagem com incentivo económico no caso do papel ....................... 31

Gráfico 14: Aceitação das propostas do WTA plástico ............................................. 34

Gráfico 15: Aceitação das propostas de WTA do vidro ............................................. 34

Gráfico 16: Aceitação das propostas de WTA do papel ............................................ 35 
Esta página foi intencionalmente deixada em branco 


\section{Lista de tabelas}

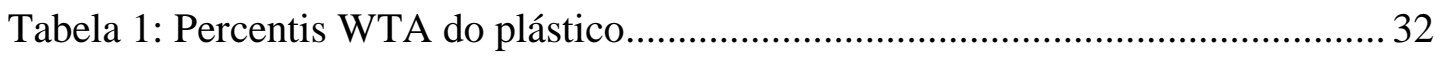

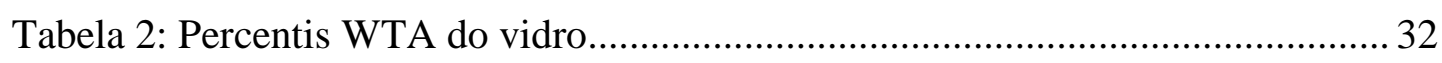

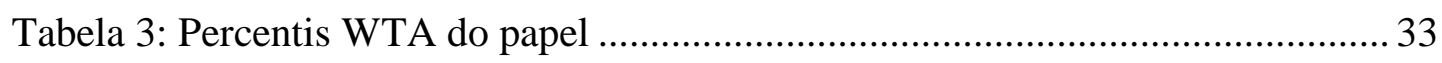

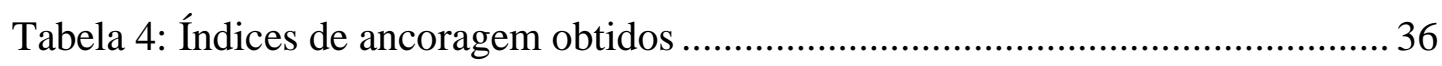

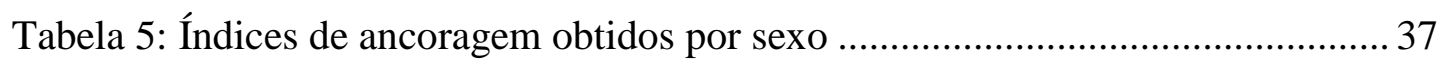


Esta página foi intencionalmente deixada em branco 


\section{Lista de siglas}

AR - Assembleia da República

EU - União Europeia

IA - Índice de Ancoragem

ONU - Organização das Nações Unidas

PAYT - Pay as you throw

SPSS - Statistical Package for Social Sciences

WTP - Willingness To Pay

WTA - Willingness To Accept 
Esta página foi intencionalmente deixada em branco 


\section{Índice}

DEDICATÓRIA III

AGRADECIMENTOS V V

$\begin{array}{lll}\text { RESUMO } & \text { VII }\end{array}$

$\begin{array}{ll}\text { ABSTRACT } & \text { IX }\end{array}$

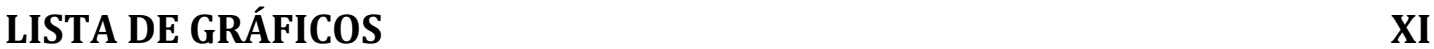

LISTA DE TABELAS _ XIII

LISTA DE SIGLAS XV X

$\begin{array}{lll}\text { ÍNDICE } & \text { XVII }\end{array}$

$\begin{array}{ll}\text { 1. INTRODUÇÃO } & 1\end{array}$

2. REVISÃO DA LITERATURA 3

$\begin{array}{ll}\text { 2.1. A Reciclagem } & 3\end{array}$

$\begin{array}{lr}\text { 2.2. Avaliação contingente } & 5\end{array}$

$\begin{array}{lr}\text { 2.3. A tomada de decisão e os vieses comportamentais } & 6\end{array}$

2.4. A heurística da ancoragem $\quad 9$

2.4.1. A ancoragem e a sua aplicação nas diferentes áreas 11

$\begin{array}{ll}\text { 2.5. Avaliação contingente e a Ancoragem } & 13\end{array}$

3. METODOLOGIA DE INVESTIGAÇÃO 16

$\begin{array}{lr}\text { 3.1. Objetivo e hipótese de investigação } & 16\end{array}$

$\begin{array}{lr}\text { 3.2. Estratégia de investigação } & 17\end{array}$ 
3.3. Definição e caracterização da amostra 19

3.3.1. Perfil dos Inquiridos $\quad 19$

3.3.2. Preocupações Ambientais dos Inquiridos 23

4. APRESENTAÇÃO E DISCUSSÃO DOS RESULTADOS 29

$\begin{array}{lr}\text { 4.1. } \text { Reciclagem com Incentivo Económico } & 29\end{array}$

$\begin{array}{lr}\text { 4.2. Valores âncora } & 31\end{array}$

4.3. Efeito ancoragem $\quad 35$

4.3.1. Testes estatísticos e índices de ancoragem 35

4.3.2. Discussão dos resultados $\quad 38$

5. CONCLUSÃO $\quad 40$

$\begin{array}{ll}\text { REFERÊNCIAS BIBLIOGRÁFICAS } & 42\end{array}$

$\begin{array}{lr}\text { ANEXOS } & 47\end{array}$ 
“As pessoas não são tão racionais quanto os livros básicos de economia pretendem descrever, e há sim, muitas situações em que elas serão irracionais. "

(Ariely, 2008) 





\section{Introdução}

Em Portugal, a reciclagem dos resíduos realiza-se numa base voluntária, isto é, não existe qualquer tipo de incentivo económico para esta prática. No entanto, em 2013, a Assembleia da República (AR) ter recomendado ao governo a adoção das políticas apresentadas pelo estudo europeu intitulado "utilização de instrumentos económicos associados à performance da gestão de resíduos", como estímulo de redução da produção de resíduos, aumento da reciclagem e diminuição dos custos e encargos dos tarifários de resíduos para as famílias (Resolução n8/2013 da Assembleia da República). De facto, em Portugal as taxas de resíduos urbanos, que variam de acordo com o município em questão, são ainda cobradas através da conta da água, supondo-se assim que a quantidade de resíduos produzidos é proporcional ao consumo de água (Ferreira \& Marques, 2015). Para uma correta implementação da referida resolução da AR torna-se assim evidente a necessidade de uma correta valorização dos incentivos económicos a utilizar.

A atribuição de um valor monetário a bens e serviços ambientais pressupõe a aplicação de métodos de avaliação específicos para bens cujo mercado não existe ainda, sendo a avaliação contingente um dos métodos utilizados para o efeito. No entanto, esta metodologia pode padecer de vieses provocados pela utilização, nomeadamente, da heurística da ancoragem, comprometendo portanto, a obtenção do valor mais adequado para estes incentivos (Green, Jacowitz, Kahneman, \& Mcfadden, 1998).

O presente estudo, pretende precisamente averiguar a existência de um efeito ancoragem relativamente aos valores que as pessoas apontam como preço necessário para fazerem reciclagem no seu dia-a-dia, quando é aplicada a metodologia de avaliação contingente.

Assim, a presente dissertação, inserida no âmbito do Mestrado em Gestão, tem por objetivo perceber, se quando expostas a uma proposta de preço a receber para passarem a fazer a reciclagem, as pessoas atribuem o preço com base nessa proposta ao invés de apontar o valor que seria efetivamente pretendido pela própria pessoa (na ausência dessa âncora).

Nesse sentido, a presente dissertação constitui um contributo para duas vertentes distintas da literatura. Para as ciências comportamentais, por um lado, ao testar a existência do efeito ancoragem no caso concreto da atribuição de um valor a pagar às pessoas para que estas passem a reciclar. Por outro lado, contribui também para a área científica da Gestão 
dos Recursos Naturais e Ambiente, ao recolher dados adicionais acerca da recetividade em Portugal a um sistema do tipo PAYT (Pay as you throw). Ao testarmos a existência de um efeito ancoragem neste tipo de valoração de bens/serviços é possível contribuir para a construção de um tarifário PAYT mais adequado em Portugal.

A presente dissertação está assim dividida em cinco capítulos distintos: o primeiro que constitui a presente introdução, o segundo apresenta a revisão da literatura dos temas abordados neste estudo e no terceiro é apresentada a metodologia utilizada para atingir os objetivos propostos e caracterizada a amostra. O quarto capítulo apresenta os resultados e a respetiva análise e, por fim, o quinto capítulo destaca as principais conclusões do trabalho apresentado. 


\section{Revisão da Literatura}

Neste capítulo, apresenta-se um enquadramento teórico dos principais temas abordados ao longo deste estudo e que servirá para sustentar o mesmo. Os temas abordados serão a reciclagem, a avaliação contingente, a tomada de decisão e os vieses comportamentais, com especial destaque para a ancoragem.

\subsection{A Reciclagem}

A reciclagem doméstica traz diversas vantagens económicas e ambientais, nomeadamente, a redução da quantidade de resíduos sólidos urbanos depositados em aterros sanitários e a diminuição da utilização de recursos naturais (Global Footprint Network, 2016). Dada a sua importância para a preservação dos recursos para as gerações futuras, diminuição da pegada ecológica e obtenção de um nível de desenvolvimento sustentável, é necessário que a prática da reciclagem seja incentivada e passe e constar cada vez mais dos hábitos diários das pessoas (Sociedade Ponto Verde, 2016).

Segundo a Global Footprint Network (2016), neste momento a humanidade para satisfazer as suas necessidades e absorver os resíduos que produz, utiliza o equivalente a 1,6 planetas, isto é, a Terra leva neste momento um ano e seis meses a regenerar as necessidades da humanidade. Esta associação acrescenta ainda que segundo a ONU, a manter-se esta tendência, em 2030 a humanidade necessitará de 2 planetas. Portugal ocupa a $27^{\circ}$ posição no ranking do Relatório Planeta Vivo 2014, ou seja os portugueses precisam de 2,6 planetas para viver neste momento: uma situação mais grave comparativamente à média mundial (WWF Portugal, 2016). Quer isto dizer que estamos a exceder a biocapacidade da Terra e, portanto, torna-se emergente, de forma a preservar as gerações futuras, tomar medidas de preservação e sustentabilidade do meio ambiente.

Uma das formas de contribuir para a preservação e sustentabilidade do meio ambiente é precisamente a prática da reciclagem, uma vez que a prática da mesma permite economizar energia, poupar matérias primas e reduzir resíduos (Sociedade Ponto Verde, 2016).

Apesar de cada vez mais, a reciclagem ser um tema do dia-a-dia e integrado nas escolas cada vez mais cedo, a União Europeia estima que cada pessoa utilize cerca de 15 toneladas 
de materiais por ano e que quase metade desses materiais sejam depositados em aterros sanitários. Para que seja possível preservar o planeta Terra e continuar a dar resposta às necessidades dos seres humanos, torna-se então necessário que num futuro próximo se faça uma transição da tradicional economia. Isto é, baseada numa linearidade de maximização do consumo, para uma economia circular, ou seja, uma economia com foco na reutilização, reparação, renovação e reciclagem dos materiais e produtos (European Commission, 2014). A economia circular revela-se uma oportunidade para reinventar a economia, tornando-a mais sustentável e competitiva (Ellen MacArthut Fundation \& McKinsey \& Company, 2014). Num planeta que cada vez mais tem dificuldades em "sustentar" a economia à escala mundial, a reciclagem é uma prática urgente.

Uma vez que atualmente em Portugal, a reciclagem é efetuada por iniciativa das pessoas, a introdução de incentivos económicos a esta prática surge como uma potencial medida pública em termos ambientais, por forma a atingir níveis superiores da prática de reciclagem. Ou seja, estes incentivos serviriam de instrumentos que atuariam no sentido de motivar as pessoas a agir de forma favorável ao ambiente, valorizando o mesmo (Aoun, 2015).

O estudo realizado por Rodrigues (2013) permitiu a análise de recetividade de uma hipotética implementação de incentivos económicos à reciclagem em Portugal. O autor concluiu que existia um potencial na aplicação e recetividade do sistema ${ }^{1}$ PAYT (Pay-asYou-Throw). Ou seja, uma eventual possibilidade de se registar um aumento do número de pessoas a separar os seus lixos em casa, se houvesse um sistema de incentivos inerentes a essa prática, premiando assim as pessoas que o fizessem. Este autor estimou ainda, o valor que seria necessário pagar para incentivar a reciclagem doméstica em Portugal com base nas respostas a um questionário, apresentando as vantagens e desvantagens da implementação de um sistema deste género.

O método utilizado por Rodrigues (2013), para a criação de um tarifário de incentivo à prática da reciclagem é denominado como modelo de avaliação contingente e será descrito na secção que se segue.

\footnotetext{
${ }^{1}$ O PAYT é um sistema que promove a participação dos cidadãos nas ações conjuntas para atingir os objetivos da política de resíduos, criando um incentivo económico. O incentivo consiste em estabelecer uma ligação entre o pagamento da taxa de recolha de resíduos e a quantidade de resíduos gerados de modo a que, a taxa paga esteja relacionada com a quantidade de lixo produzida por cada cidadão (Batllevell \& Hanf, 2008).
} 


\subsection{Avaliação contingente}

A avaliação contingente é uma ferramenta poderosa e versátil, utilizada pela economia ambiental, para medir o valor dos bens económicos não comercializados de forma consistente e conforme a teoria económica (Mitchell \& Carson, 1989).

Assim, esta metodologia tem a capacidade de estimar o valor económico de um produto ou projeto para o qual não existe um preço de mercado, como é o caso dos bens ambientais, facilitando assim a tomada de decisão pública ao fornecer uma estimativa dos benefícios obtidos com a implementação de projetos ambientais e do aumento do bem-estar da sociedade (Carson, 2000).

Este método envolve a utilização de inquéritos por amostragem (Portney, 1994) e tem assim, como objetivo, medir o valor monetário de um indivíduo para algum item (Carson \& Hanemann, 2005), tendo como base teórica a estrutura da função utilidade e a teoria econométrica (Ferreira \& Marques, 2015). No fundo, é possível afirmar que este modelo cria, com base na opinião das pessoas o preço de determinado bem que não tem preço de mercado definido, como é o caso dos bens ambientais.

Através do instrumento de pesquisa, utilizado no modelo de avaliação contingente obtémse quer o valor de WTP (willingness to pay), ou seja, de disponibilidade para pagar, quer da disponibilidade para aceitar ou receber (WTA-willingness to acept) a mudança na qualidade do meio ambiente. Assim sendo, a avaliação contingente pode desempenhar um papel fundamental na definição de políticas públicas na medida em que, ao valorizar este tipo de bens, está de certa forma a permitir que os políticos possam negociar medidas com base nestes valores (Portney, 1994).

Existem assim duas medidas padrão para um valor económico: o WTP, que é a medida utilizada numa situação em que se pretende adquirir ou obter um bem e, por outro lado, o WTA, que é a medida utilizada numa situação em que se pretende que alguém desista/abdique de um bem. No caso dos bens ambientais, se o consumidor não usufrui desse bem nem tem direito a ele, então a medida a utilizar é o WTP. Se, no caso contrário, o consumidor tem direito e usufrui de um bem e estiver a ser convidado a abdicar dele, então a medida certa é o WTA (Carson, 2000). 
O modelo de avaliação contingente baseia-se assim, em questionários para obter as preferências dos indivíduos relativamente ao valor dos bens públicos e descobrir os valores que eles estariam dispostos a receber, ou a pagar, por melhorias concretas nesses mesmos bens. Este modelo contorna assim a ausência de mercados de bens públicos, apresentando aos consumidores mercados hipotéticos em que têm a oportunidade de comprar o bem em questão, sendo esta a sua principal vantagem. No entanto, como esclarecem Mitchell \& Carson (1989), este método não é isento de erros e as suas principais limitações são a precisão, credibilidade e a fiabilidade das respostas que os indivíduos dão aos questionários. Sendo estas variáveis difíceis de controlar, são de facto o ponto fraco deste tipo de modelo.

Num estudo de avaliação contingente são utilizados dois tipos de questionários: o primeiro solicita aos inquiridos, através de questões de resposta aberta, que apontem um valor para um determinado bem. O outro tipo de questionário baseia-se na utilização de um referendo, ou seja, é colocada uma questão com opções de resposta "sim" ou "não". Por outro lado, uma questão de resposta fechada, em que perante as opções apresentadas, se pede aos inquiridos que optem por aquela que lhe parece ser o valor que estão dispostos a pagar ou dispostos a aceitar para uma mudança específica ou ainda, que perante o valor apresentado manifeste se o aceita ou se o recusa (Arrow et al., 1993).

Como todos os questionários, não só os utilizados nos estudos de avaliação contingente, estão sujeitos a uma tomada de decisão por parte dos inquiridos para cada questão. A próxima secção aborda o tema da tomada de decisão e os vieses comportamentais que possam surgir.

\subsection{A tomada de decisão e os vieses comportamentais}

Para que a determinação do WTP ou WTA seja fidedigna, é necessário que as respostas dadas pelos indivíduos ao instrumento de pesquisa sejam válidas e lógicas refletindo assim o verdadeiro valor de determinado bem. 
Teoricamente, um indivíduo racional quando submetido a um processo de escolha entre várias alternativas, opta por aquela que lhe proporciona a combinação que resulta no melhor resultado ou na maior satisfação possível (Gilovich, Griffin, \& Kahneman, 2002).

No entanto, a tomada de decisão é uma complexa atividade do cérebro humano que tem como base alguns instrumentos, como é o caso dos fatores emotivos e intuitivos, sendo a partir destes que se geram as decisões, que se esperam ótimas, eficientes e eficazes mas que, em determinadas situações, podem ter o efeito inverso. Ou seja, as emoções e as intuições tornam-se uma espécie de obstáculo à tomada de decisão racional (Altman, 2012).

Durante o processo de tomada de decisão, as pessoas pretendem reduzir a complexidade do problema de modo a simplificar a sua solução. Para isso, nestas situações baseiam-se em crenças, julgamentos intuitivos e probabilidades de eventos incertos fundamentados em princípios heurísticos e em probabilidades subjetivas (Tversky \& Kahneman, 1974).

O conceito de racionalidade limitada, autoria de Herbert Simon, coloca em questão racionalidade do indivíduo na tomada de decisão ótima. Põe em causa a capacidade íntegra do indivíduo escolher a mais estável e consistente das suas alternativas por forma a maximizar e atingir os seus objetivos (Barros, 2004).

Simon (1965) explica que o indivíduo desconhece a totalidade das suas alternativas e, como tal, as consequências das mesmas. Assim sendo, o comportamento humano limita a teoria económica e administrativa.

Também de acordo com Ariely (2008), o ser humano é irracional, comete erros sistematicamente e age por impulso frequentemente, o que só por si vem explicar a economia comportamental e a razão desta contrariar o modelo tradicional que associa o economista a decisões corretas e racionais. Os economistas são também humanos o que torna difícil esta radicalidade em termos de tomada de decisões racionais e assertivas (Ariely, 2008). No entanto, Simon (1994) afirma que a limitação da racionalidade pode ser minimizada pelo conhecimento racional, ou seja, quando um indivíduo tem um grau de conhecimento elevado relativo a um tema, sob o qual terá que tomar uma decisão, este é menos suscetível de ser influenciado por vieses comportamentais.

Segundo Nofsinger (2006), os erros comportamentais são provocados por enviesamentos, nomeadamente: a autoilusão provocada pelo excesso de confiança, a simplificação da 
informação ao processar a mesma, a influência da opinião dos outros, o medo e o humor. Assim sendo, apresentam-se em seguida alguns dos vieses comportamentais existentes:

1. As empresas e as pessoas no geral demonstram frequentemente comportamentos de aversão ao risco e a resultados desfavoráveis. É possível identificar este viés cognitivo quando as decisões são tomadas tendo em conta este sentimento (Guo, Wong, Xu, \& Zhu, 2015).

2. A dissonância cognitiva acontece quando uma pessoa tem certos elementos cognitivos que são "conhecimentos" sobre si mesmo, o seu ambiente, as suas atitudes, as suas opiniões, e os seus comportamentos passados e estes elementos não seguem uma lógica entre si. Por outras palavras, este viés cognitivo pode ser explicado quando em simultâneo, a pessoa apresenta ideias e opiniões contraditórias (Oshikawa, 1969).

3. O efeito ancoragem é a influência despropositada de valores inicialmente apresentados na tomada de decisão (Tversky \& Kahneman, 1974).

4. Contabilidade mental é o conjunto de operações cognitivas utilizadas pelos indivíduos para organizar, avaliar e acompanhar as atividades financeiras (Thaler, 1999).

5. O excesso de confiança é verificado quando existe uma sobrestima das próprias capacidades, isto é, existe uma confiança superior em relação a alguma coisa do que aquilo que seria mais realista (Klayman, Soll, Claudia, \& Barlas, 1999).

6. Os investidores sujeitos à heurística da representatividade têm tendência a sobrestimar informações recentes e avaliar a probabilidade de um acontecimento com base nestes dados (Boussaidi, 2013).

7. O conservadorismo é um enviesamento cognitivo em que as pessoas apresentam dificuldade em atualizar as suas ideias, valorizando em excesso as informações e ideias do passado (Luo, 2012).

8. Quando existem situações em que as pessoas avaliam a frequência de uma situação, ou a probabilidade de um evento pela facilidade com que instâncias e acontecimentos podem ser trazidos à mente, então estamos perante o enviesamento da disponibilidade. Por exemplo, quando se avalia o risco de ataque cardíaco entre as pessoas de meia-idade, recordando situações entre os próprios conhecidos (Tversky \& Kahneman, 1974). 
9. Está-se perante o enviesamento da retrospetiva quando existe uma tendência dos indivíduos fazerem estimativas de probabilidade de determinadas ocorrências mais elevadas depois dessas mesmas ocorrências terem acontecido (Agans \& Shaffer, 1994).

10. O enviesamento do excesso de otimismo é verificado quando há um otimismo irrealista em que existe uma crença (muitas vezes errada) de que, se o problema ainda não aconteceu, é improvável que aconteça no futuro (Weinstein, 1987).

11. O enviesamento da confirmação é verificado quando um indivíduo conota com demasiada importância as informações e evidências que validam perceções e expectativas pré-existentes e desvaloriza as informações e evidências que as contrariam (Nickerson, 1998).

12. O status-quo significa não fazer nada, manter uma decisão atual ou uma decisão anterior perante determinadas tomadas de decisão. Perante as condições existentes, o indivíduo opta pela decisão que confirme as mesmas (Samuelson \& Zeckhauser, 1988).

De entre estes vieses comportamentais apresentados, pretende-se dar agora destaque à heurística da ancoragem por ser um desvio comportamental que, através de valores inicialmente apresentados num dado processo, é capaz de influenciar valores numéricos surgidos num processo de tomada de decisão.

\subsection{A heurística da ancoragem}

O efeito ancoragem é definido como a influência despropositada de valores inicialmente apresentados no processo de tomada de decisão. Ou seja, em diversas situações as pessoas fazem ajustamentos próprios e estimam com base em valores ou parâmetros, que inicialmente lhes foram apresentados (Tversky \& Kahneman, 1974). Furnham \& Boo, (2011) explicam que este é um efeito extremamente robusto e pode ser demonstrado numa grande variedade de tarefas de tomada de decisão, com diferentes grupos e em diferentes configurações.

Conclui-se assim, que diferentes pontos de partida resultam em estimativas diferentes, que são inclinadas para os valores iniciais, ainda que esses valores iniciais ou âncoras possam 
não fazer sentido (Epley \& Gilovich, 2006) ou ainda que hajam orientações para desconsiderar esses mesmos valores (Strack \& Mussweiler, 1997).

Os valores âncora são muitas vezes referências erradas, como concluem os diversos estudos em torno do tema da ancoragem, mesmo os valores meramente informativos que surgem nas situações de tomada de decisão e julgamento (Furnham \& Boo, 2011). Critcher $\&$ Gilovich (2008) descobriram inclusivamente que as estimativas de desempenho de um atleta podem ser ancoradas pelo número de camisola. A previsão de vendas pode ser influenciada pelo número do modelo do produto e as previsões de gastos de um restaurante afetadas pelo nome do restaurante ( "Studio 17" ou "Studio 97").

No seu estudo pioneiro relativamente à ancoragem, Tversky \& Kahneman (1974) atribuíram aos participantes da investigação um número arbitrário entre 0 e 100 e foram convidados a indicar se a percentagem de países africanos nas Nações Unidas seria maior ou menor do que aquele número. Os resultados dessa investigação provaram claramente que as respostas finais foram influenciadas pelo valor inicial atribuído pelo investigador, ou seja, os participantes que tinham recebido um número relativamente alto deram estimativas absolutas mais elevadas do que os participantes que receberam um número inferior.

O valor âncora serve como ponto de referência para as pessoas ajustarem o limite do intervalo de valores plausíveis para a questão. Os diversos estudos realizados ao longo dos anos sobre este efeito, demonstram que o processo de ajustamento entra em jogo quando os valores de referência são apresentados e os participantes ajustam ligeiramente a partir desses mesmos valores que julgam ser perto da resposta certa (Strack \& Mussweiler, 1997). Verificando-se que quando expostas a uma âncora superior, as pessoas fazem ajustes insuficientes para baixo e vice-versa (Tversky \& Kahneman, 1974).

Wilson, Houston, Etling, \& Brekke (1996), esclarecem que o viés da ancoragem é verificado na ausência de qualquer instrução explícita para comparar a âncora e o alvo. Acrescentam ainda que a ancoragem é um processo muito comum e provável de surgir em contextos naturais e do dia-a-dia.

Apesar disto, Furnham \& Boo (2011) explicam que as pessoas são mais ou menos influenciadas pelas âncoras consoante o seu nível de conhecimento dos indivíduos sobre o tema em questão. Isto é, quando as pessoas têm níveis de conhecimentos mais reduzidos na 
matéria sobre a qual têm de fazer um julgamento ou tomar uma decisão, estas são mais influenciadas pelas âncoras que lhes são apresentadas. Por outro lado, quando as pessoas têm níveis de conhecimento mais elevados na matéria sobre a qual têm de fazer um julgamento ou tomar uma decisão, estas são menos influenciadas pelas âncoras.

É no entanto importante destacar que, como referem Wilson et al. (1996), apesar dos indivíduos com maiores conhecimentos do tema ao qual são levados a julgar/tomar uma decisão, serem menos influenciados pelas âncoras apresentadas, não estão isentos do efeito, sendo possível verificar o mesmo nesta situação. Por exemplo numa situação em que especialistas do ramo automóvel (mecânicos de automóveis e revendedores), com todas as informações necessárias, acabam por avaliar o valor de um carro com base nas âncoras fornecidas (Mussweiler, Strack, \& Pfeif, 2000).

Portanto, o efeito ancoragem afigura-se de forma não intencional e de forma inconsciente, sendo por isso difícil de evitar, mesmo quando as pessoas estão prevenidas para a existência deste efeito (Wilson et al., 1996).

Para se determinar a possível existência do efeito ancoragem numa determinada situação, Jacowitz \& Kahneman (1995) explicam que são necessários três grupos de indivíduos extraídos da mesma população. Um primeiro grupo é designado por grupo de calibragem e fornece as estimativas de um conjunto de quantidades incertas, sem âncoras. Os restantes dois grupos oferecem essas estimativas após a apresentação de uma âncora, sendo as âncoras selecionadas pela sua posição na distribuição das estimativas do grupo de calibragem, geralmente definidos o primeiro e o terceiro quartis como âncora baixa e âncora alta, respetivamente.

\subsubsection{A ancoragem e a sua aplicação nas diferentes áreas}

Numa situação de tomada de decisão, a heurística da ancoragem pode ser uma das maiores influências, conforme esclarecem Strack \& Mussweiler (1997), isto porque, este efeito é verificado em diversas áreas de estudo onde ocorrem situações em que as pessoas são levadas a tomar uma decisão. Torna-se assim, importante que se possa detetar este efeito para que ele possa ser utilizado como estratégia de negociação. 
As finanças comportamentais agregam, além das finanças tradicionais, influências das teorias da psicologia e sociologia, de forma a tentar explicar anomalias de mercado. $\mathrm{Ou}$ seja, enquanto nas finanças tradicionais as pessoas são vistas como racionais, nas finanças comportamentais, elas são vistas como são na verdade, suspeitas de cometerem erros cognitivos nas avaliações que fazem (Ramiah, Xu, \& Moosa, 2015).

Segundo Lobão (2012, p.10), “as finanças comportamentais são uma corrente de estudo em Finanças que flexibiliza o pressuposto da racionalidade completa aproveitando $o$ conhecimento acerca da forma como os indivíduos se comportam".

O efeito ancoragem é uma das heurísticas cognitivas mais robustas e tem diversas aplicações em todo o processo de tomada de decisão, mas é também o efeito que expõe os seus utilizadores a vieses e que inconscientemente os leva a tomar decisões erradas (Tversky \& Kahneman, 1974).

Existem inúmeros estudos acerca desta heurística por diversas áreas: No caso das decisões de compra do consumidor e julgamento de preços de produtos básicos, por exemplo, os estudos já realizados concluem que os consumidores são fortemente influenciados pelo efeito ancoragem, quer em termos de realização de estimativas de quantidades incertas, quer em termos de preços (Junior \& Mauriz, 2011; Luppe, 2006; Neto, Filipe, \& Ramalheiro, 2011).

Naquilo que diz respeito ao setor imobiliário, os estudos já realizados comprovam que são notórios os efeitos da ancoragem nos investimentos imobiliários e que, em situações em que pessoas avaliam investimentos, valores que podem ser arbitrários podem influenciar a estimativa das pessoas (Dorow, Júnior, Nunes, Reina, \& Maximiniano, 2010; Tronco, Löbler, \& Nishi, 2013).

Também no setor financeiro foram já testados os efeitos da ancoragem, verificando-se que este setor é também bastante influenciado pela racionalidade limitada do ser humano e pelo efeito ancoragem (Da Silva \& Naldis, 2012). Por exemplo, no caso dos investimentos, diversos autores explicam que as decisões de investimentos em ativos financeiros são muitas vezes influenciadas por resultados anteriores (Altman, 2012).

Em termos de gestão de recursos humanos, foi verificada também a influência do efeito ancoragem na avaliação dos curriculum vitae. Neste caso em particular, foram verificadas âncoras de conteúdo, nomeadamente a imagem de um bombeiro e a história comovente de 
um salvamento por um bombeiro e verificou-se que os participantes tendem a avaliar de forma mais positiva o CV de um candidato que é Bombeiro Voluntário (Magalhães, 2013).

\subsection{Avaliação contingente e a Ancoragem}

Quando estamos perante um modelo de avaliação contingente, surgem duas frequentes fontes de enviesamentos: em primeiro lugar, surge a tendência dos inquiridos estimarem valores demasiado altos dos incentivos económicos com a expectativa, ainda que inconsciente, de vir mesmo a receber estes montantes e depois a segunda fonte de enviesamento é a ancoragem (Green et al., 1998).

Num instrumento de investigação como é o questionário, espera-se que os inquiridos façam uma escolha racional, no entanto a incerteza em relação aos resultados pode dificultar essa racionalidade e no caso de estarmos a procurar obter valores de WTP e WTA, estes podem surgir enviesados (Kato \& Hidano, 2007).

No fundo, é possível perceber que se a avaliação contingente tem como principal objetivo encontrar o valor económico para um produto ou projeto ambiental e se para isso são utilizados questionários com o objetivo de angariar dados juntos dos indivíduos, esta avaliação está sujeita a enviesamentos comportamentais. No caso da ancoragem, os efeitos são frequentemente observados quando as pessoas são convidadas a apontar números incertos e portanto, é possível concluir que todos estes temas se cruzam inevitavelmente (Gilovich et al., 2002).

Utilizando questões de resposta aberta num questionário de avaliação contingente, geramse valores demasiado elevados ou demasiado baixos para serem fiáveis (Green et al., 1998). No caso de serem utilizadas questões de resposta fechada, onde perante um valor apontado, os inquiridos respondem sim ou não, facilita-se o processo de tomada de decisão do inquirido (Mitchell \& Carson, 1989). Surge assim, uma possível influência do valor proposto na própria questão sobre a resposta do indivíduo à pergunta. Isto é, diferentes valores iniciais podem levar os inquiridos a apontar diferentes WTP ou WTA e, portanto, levar a estimativas diferentes e, consequentemente, a diferentes decisões públicas (Aprahamian, Chanel, \& Luchini, 2007). 
Quando uma investigação procura obter através da avaliação contingente, valores monetários, o lance inicial pode ser considerado pelo entrevistado como uma indicação da qualidade do bem contingente e ancorar a sua resposta no valor proposto na própria questão. Existe assim, uma tendência para os inquiridos responderem afirmativamente ou concordarem com a afirmação do entrevistador, independentemente das suas verdadeiras opiniões (Mitchell \& Carson, 1989). Também Herriges \& Shogren (1996) alerta para o facto da eficácia da informação retirada dos questionários de avaliação contingente poder ser posta em causa pelo fenómeno da ancoragem.

Acontece que muitas vezes, os indivíduos inquiridos não têm conscientemente uma opinião formalizada em relação ao tema das questões (Hanemann, 1985). Num questionário de avaliação contingente, estamos perante este problema quando uma pessoa é questionada relativamente ao valor de um bem. Caso a pessoa conheça este bem, à partida poderá dar uma resposta "fiável", mas por outro lado se a pessoa não conhece ou não valoriza esse bem, a sua resposta não será significativa, uma vez que o indivíduo não sabe o valor do bem. Nesta ultima situação, caso o indivíduo esteja perante uma questão que apresenta hipóteses de valor para a resposta, então a pessoa inquirida pode ser induzida a responder com base nesses valores apresentados, ao invés de traduzir na resposta a sua própria opinião.

Esta possível influência do efeito ancoragem num estudo de avaliação contingente, pode levar a resultados e conclusões enganosos, uma vez que os indivíduos reagem de forma diferente conforme os valores apontados nas questões (Aprahamian et al., 2007). Sendo a avaliação contingente muitas vezes utilizada como instrumento de apoio às políticas públicas, torna-se relevante avaliar o impacto deste efeito neste tipo de estudos, para que as informações dadas por este tipo de avaliação sejam fidedignas (Kato \& Hidano, 2007).

Também Green et al. (1998), defendem que os vieses cognitivos podem revelar-se um grande problema naquilo que diz respeito à influência dos mesmos nos incentivos económicos para bens públicos. A avaliação contingente pode dar indicações erradas, uma vez que as respostas às perguntas do respetivo referendo deste tipo de avaliação, são muitas vezes dadas sobre influência dos valores induzidos (âncoras).

Apesar de terem já sido desenvolvidos esforços no sentido de se corrigirem este tipo de vieses comportamentais, Flachaire \& Hollard (2006) esclarecem que os modelos que 
tentam corrigir o efeito dos vieses nos questionários, provocam a perda da eficiência das perguntas apresentadas no questionário.

Por fim, é possível concluir que, sendo a reciclagem uma necessidade urgente e para a qual é necessário alcançar níveis mais elevados, os incentivos económicos podem ser um impulso para a obtenção de níveis mais elevados dessa prática. Para perceber o "preço da reciclagem", isto é, o valor necessário a pagar às pessoas para as incentivar a reciclar, sendo a reciclagem um bem ambiental, é possível utilizar o modelo de avaliação contingente para obter esse valor.

Como se expôs anteriormente, a avaliação contingente está sujeita a tomadas de decisão por parte dos inquiridos e como tal, estas tomadas de decisão podem ser acompanhadas por vieses comportamentais que muitas vezes surgem neste tipo de situação.

A secção que se segue, apresenta a metodologia utilizada no presente estudo, de forma a averiguar a possível existência de um efeito ancoragem num modelo de avaliação contingente para obtenção do valor WTA da reciclagem. 


\section{Metodologia de Investigação}

Este capítulo apresenta a metodologia utilizada ao longo do presente estudo, encontrandose organizado em três secções que descrevem, respetivamente: o objetivo e hipótese de investigação; os instrumentos de pesquisa adotados e apresenta a amostra utilizada nomeadamente em termos de perfil e em termos de preocupações ambientais.

\subsection{Objetivo e hipótese de investigação}

A presente dissertação de mestrado teve como principal objetivo verificar a possível existência do efeito ancoragem no valor que as pessoas apontam como incentivo económico necessário para que pratiquem a reciclagem no seu dia-a-dia. A avaliação da eventual existência deste efeito, irá permitir retirar conclusões naquilo que diz respeito ao valor da eventual tarifa PAYT para a reciclagem doméstica e, em caso da aplicação do mesmo sistema, contribuir de forma relevante na construção do tarifário.

Como vimos no capítulo anterior, ao longo dos anos, foram sendo realizados diversos estudos com o objetivo de identificar a possível existência de um efeito ancoragem em diversos temas, inclusivamente no que respeita à valorização dos bens públicos, dado que os estudos de avaliação contingente são considerados bastante vulneráveis a este efeito (Green et al., 1998). Assim, o presente estudo contribui para a literatura, apresentando dados adicionais para o caso concreto da valorização dos incentivos económicos à reciclagem em Portugal.

Partindo do estudo de Rodrigues (2013) acerca dos incentivos económicos à prática da separação dos lixos em Portugal, a presente dissertação pretende testar a existência, ou não, de um efeito ancoragem na valorização obtida a partir da aplicação da metodologia de avaliação contingente, traduzindo-se este na seguinte hipótese de investigação:

H1: Existência de um efeito ancoragem na determinação do valor de incentivo económico que as pessoas necessitariam de receber para reciclar no seu dia-a-dia. 


\subsection{Estratégia de investigação}

A estratégia de investigação para testar a hipótese apresentada consistiu na realização de um survey. Para o efeito, foram desenvolvidos três questionários distintos conforme Jacowitz \& Kahneman (1995), com base no questionário utilizado por Rodrigues (2013) aquando do seu estudo sobre a implementação de incentivos económicos à prática da reciclagem, que podem ser consultados nos anexos n. ${ }^{\circ} 1$, n. ${ }^{\circ} 2$ e n..$^{\circ} 3$.

O questionário n. ${ }^{\circ}$, adotado para o grupo de calibragem, serviu para obter estimativas absolutas do valor que os indivíduos da amostra necessitavam de receber (WTA) para reciclarem e ainda para determinar os valores das âncoras alta e baixa, posteriormente utilizadas nos questionários $\mathrm{n} .{ }^{\circ} 2$ e n. $^{\circ} 3$. Os valores âncora foram construídos a partir dos dados recolhidos através do grupo de calibragem (Green et al., 1998), correspondendo a âncora baixa ao percentil 25 e a âncora alta ao percentil 90 .

Em comum, nos três questionários, são incluídas questões relacionadas com a caracterização socioeconómica da amostra (na secção "Perfil do Inquirido"), ou seja, questões relativas ao género, idade, grau de estudos e rendimento mensal. Adicionalmente, os três questionários, continham ainda seis questões relativas a comportamentos do dia-adia que podem traduzir preocupações ambientais por parte do inquirido (secção designada "Preocupações Ambientais"). Nomeadamente, a frequência com que os inquiridos efetuam a reciclagem, enchem a máquina de lavar loiça e roupa antes de as colocar a funcionar, se compram papel reciclado, se reutilizam sacos de plástico, se utilizam lâmpadas de baixo consumo e a frequência com que compram produtos com o rótulo ecológico.

Naquilo que diz respeito à secção distinta entre os três questionários, esta era denominada de "Reciclagem com Incentivo Económico". Nesta secção, mantinha-se uma questão em comum nos três questionários, onde era perguntado em separado, para os três materiais plástico, vidro e papel, se as pessoas aceitariam reciclar sempre o respetivo material, se a essa prática estivesse associada uma recompensa monetária. Existindo aí quatro opções de resposta: "sim”, "não", "talvez” ou "já reciclo sem recompensa”. No caso do questionário do grupo de calibragem seguia-se uma pergunta de resposta aberta, onde era pedido aos inquiridos que apontassem o valor que necessitariam de receber por cada quilo do respetivo material reciclado. No caso dos grupos experimentais, depois da primeira questão, seguia-se nesta secção, uma pergunta/proposta com o valor âncora do respetivo 
grupo experimental ("se o governo obrigasse as empresas de recolha seletiva a pagar $x$ (valor âncora) euros por kg de $y$ (plástico, vidro ou papel) que cada indivíduo reciclasse, concordaria com esta medida?"), sendo as opções "sim" ou "não". Apenas depois desta questão, surgia nos grupos experimentais a pergunta de resposta aberta que pedia aos inquiridos que apontassem o valor que necessitariam de receber por cada quilo do respetivo material reciclado.

Após a elaboração do questionário $\mathrm{n} .^{\circ} 1$, foi aplicado um pré-teste a 10 indivíduos, selecionados por conveniência, para que este fosse posteriormente aplicável com êxito. $\mathrm{O}$ pré-teste antecedeu, portanto, a fase definitiva de recolha de dados, evitando que a mesma fosse prejudicada por algum erro no questionário (Sousa, M. J., \& Baptista, 2011). Com base nos resultados deste primeiro pré-teste, foram realizadas algumas alterações no questionário de modo a que este se tornasse mais claro e que não apresentasse questões irrelevantes para a questão de investigação. Foi então realizado um novo pré-teste a 5 inquiridos e o questionário foi validado.

Para analisar a possível existência de um efeito ancoragem, foi utilizado o índice de ancoragem, desenvolvido por Jacowitz \& Kahneman (1995) que utiliza as medianas do grupo de calibragem e do grupo experimental e ainda os valores âncoras. Este índice é calculado pela seguinte fórmula:

$$
I A=\frac{\text { Mediana }(\hat{a} n c o r a \text { alta })-\text { Mediana }(\hat{a} n c o r a ~ b a i x a)}{\hat{A} n c o r a \text { alta }-\hat{\text { Âncora baixa }}}
$$

Este índice pode ser também calculado separadamente para cada tipo de âncora, sendo assim:

$$
I A(\hat{a} n c o r a \text { baixa })=\frac{\text { Mediana }(\text { âncora baixa })-\text { Mediana }(\text { grupo de calibragem })}{\text { Âncora baixa }- \text { Mediana }(\text { grupo de calibragem })}
$$

Ou no caso do IA (âncora alta):

$$
I A(\text { âncora alta })=\frac{\text { Mediana }(\text { âncora alta })-\text { Mediana }(\text { grupo de calibragem })}{\text { Âncora alta }- \text { Mediana }(\text { grupo de calibragem })}
$$




\subsection{Definição e caracterização da amostra}

Para constituição do grupo de calibragem foram distribuídos 300 questionários em papel, sendo validados 199 dos mesmos. No caso do grupo experimental da âncora alta e do grupo experimental da âncora baixa foram criados dois questionários distintos numa plataforma online. Posteriormente, os respetivos links foram partilhados para obtenção de respostas através das redes sociais e através de email, tendo sido o primeiro respondido por 169 pessoas e o segundo por 229. No total dos 3 questionários responderam 597 pessoas. Esta amostra é denominada amostra por conveniência, uma vez que a mesma é voluntária e os seus elementos foram selecionados por uma questão de conveniência (Hill, M. M., \& Hill, 2000).

\subsubsection{Perfil dos Inquiridos}

O grupo de calibragem da amostra ou questionário número 1 é composto por 126 indivíduos do sexo feminino e 73 indivíduos do sexo masculino. As idades estão compreendidas entre os 17 e os 64 anos de idade, com uma idade média de 25 anos e no geral, regista-se uma maior concentração de indivíduos da amostra com idades até aos 25 $\operatorname{anos}(73,4 \%)$.

No caso do questionário número 2, ou grupo experimental da âncora alta, o mesmo é composto por 100 indivíduos do sexo feminino e 69 indivíduos do sexo masculino. Em termos de idades, estas estão compreendidas entre os 17 e 63 anos e a média de idades é de cerca de 33 anos. De destacar que, na amostra que respondeu a este questionário os grupos de idades estão bastante equilibrados em termos de número de pessoas pertencente a cada classe, com apenas a classe de idades com 46 ou mais anos a representar uma parte mais pequena do grupo $(11,2 \%)$.

Naquilo que diz respeito ao questionário número 3, ou grupo experimental da âncora baixa, este foi respondido 229 indivíduos, 128 deles pertencentes ao sexo feminino e 101 ao sexo masculino. As idades variaram entre os 14 e os 63 anos e a média de idades, tal como no questionário anterior, foi de 33 anos. Neste caso, a maior percentagem de indivíduos 
concentra-se na classe de idades até aos 25 anos (31,6\%) seguido do grupo entre os 36 e os 45 anos (28,5\%). Apesar de este grupo apresentar o mínimo de idades mais baixa (14 anos) comparativamente aos grupos dos restantes 2 questionários, destaca-se pela maior percentagem de inquiridos com mais de 46 anos (14\%).

Em termos gerais, os três questionários foram sempre mais respondidos por indivíduos do sexo feminino, sendo esta maior diferença no grupo de calibragem, onde as mulheres responderam a mais de $63 \%$ dos questionários.

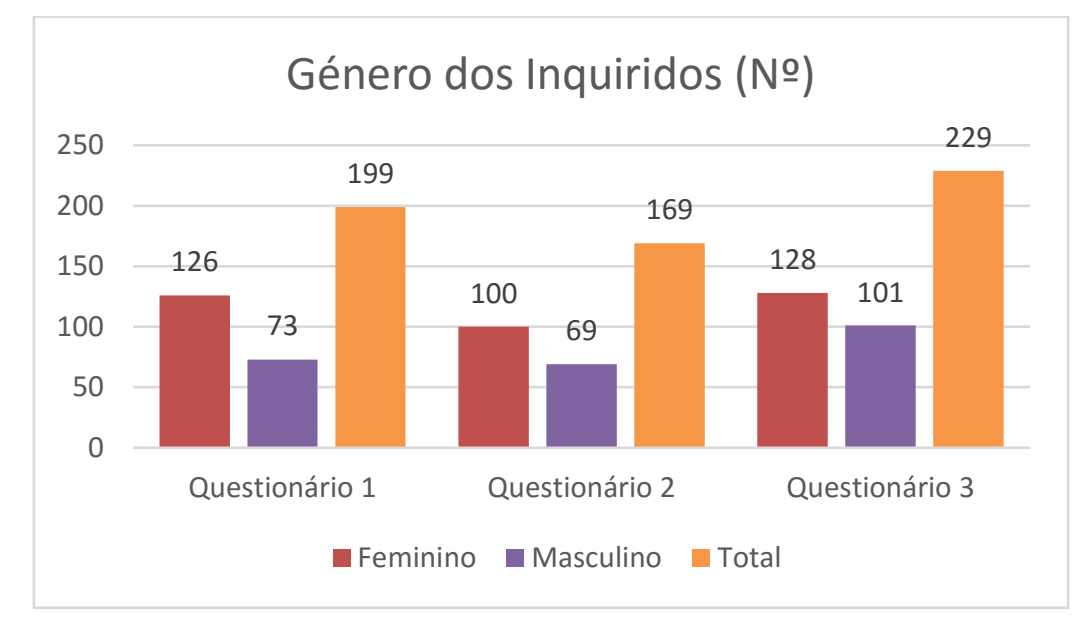

Gráfico 1: Género dos Inquiridos

Em termos de idades, é possível verificar que o grupo de calibragem é claramente mais jovem quando comparado com os grupos experimentais, grupos estes que poderão ser considerados bastante equilibrados uma vez que tirando a classe de idades com mais de 46 anos, as classes encontram-se com número de indivíduos relativamente próximo. 


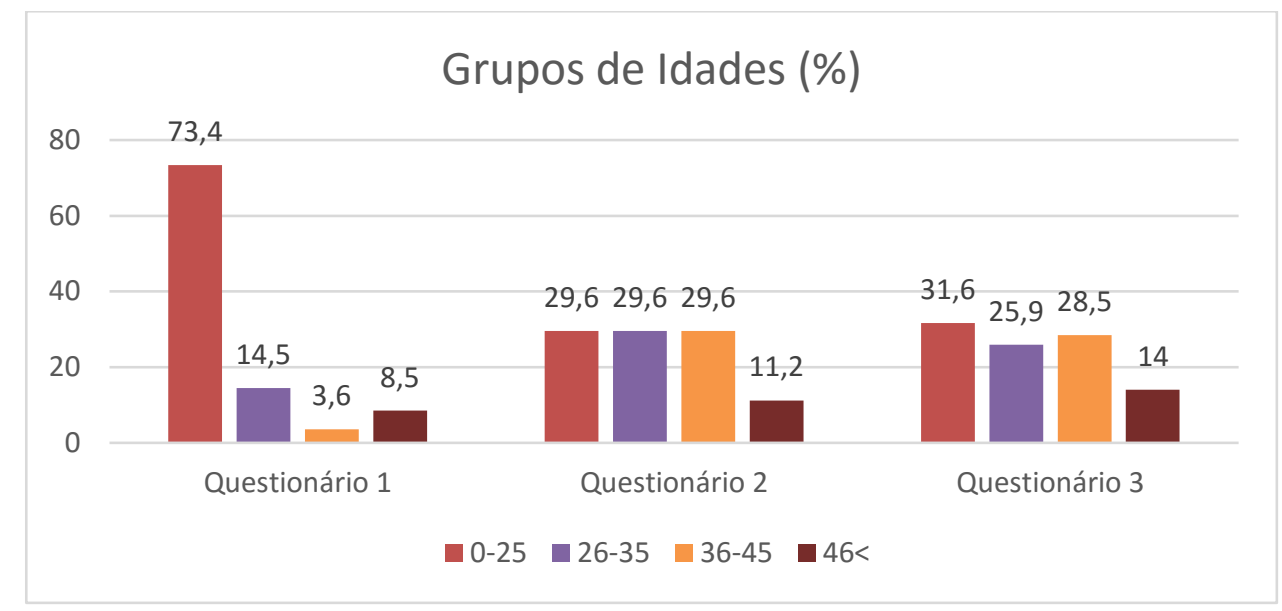

Gráfico 2: Idades dos Inquiridos

A justificação para o facto do grupo de calibragem apresentar um grande número de inquiridos com idades até aos 25 anos, pode prender-se com o facto de este questionário ter sido distribuído em papel, maioritariamente, nas instalações da Escola Superior de Tecnologia e Gestão do Instituto Politécnico de Leiria.

Em termos de habilitações literárias da amostra, no grupo de calibragem (questionário n. ${ }^{\circ}$ 1) verifica-se que cerca de $40 \%$ dos indivíduos da amostra se encontra a frequentar uma licenciatura ou um mestrado, cerca de $31 \%$ dos indivíduos têm o ensino secundário e cerca de $18 \%$ têm uma licenciatura ou um bacharelato. No grupo experimental da âncora alta (questionário n. ${ }^{\circ}$ ), a maioria dos indivíduos $(43,79 \%)$ possui uma licenciatura/bacharelato, tal como acontece com o grupo experimental da âncora baixa onde aqueles que possuem uma licenciatura/bacharelato representam cerca de $37 \%$ do grupo.

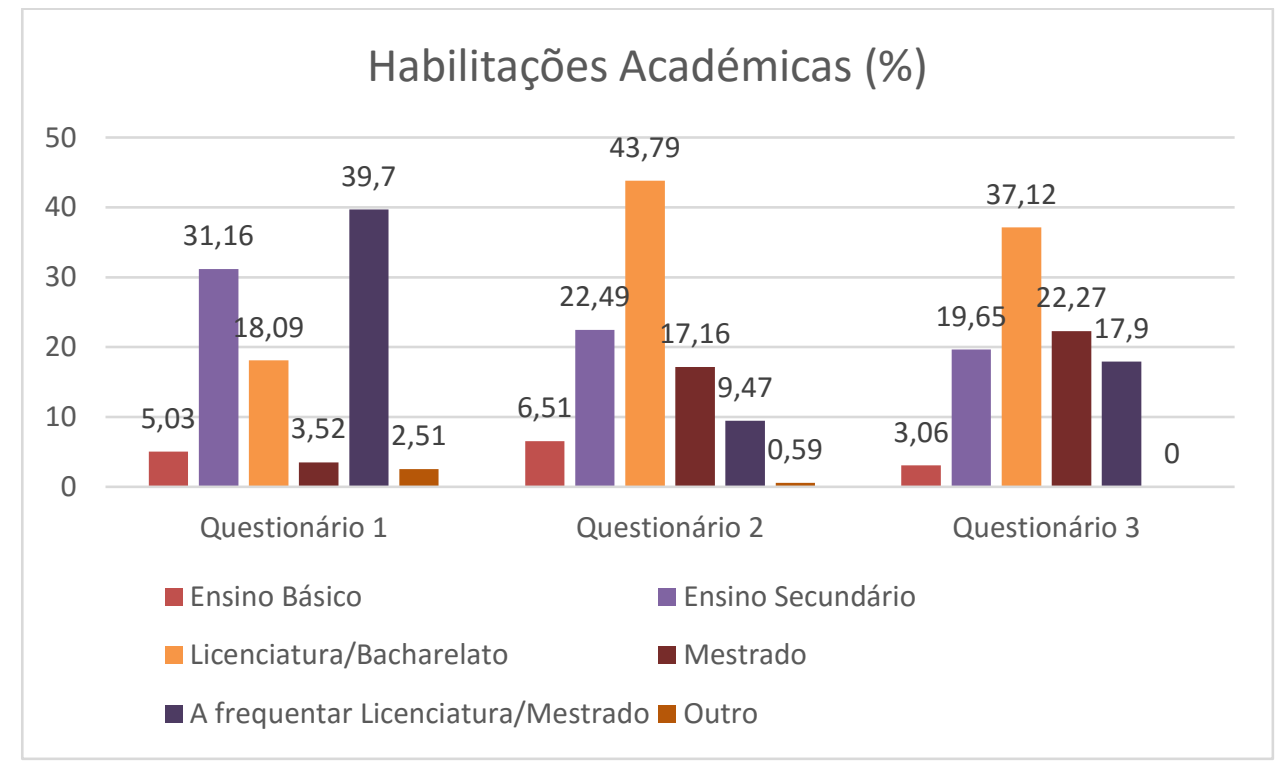

Gráfico 3: Habilitações académicas dos inquiridos 
Em termos gerais, tal como aconteceu com as idades, este dois grupos (questionários $\mathrm{n}^{\circ} 2 \mathrm{e}$ n³) revelam-se mais ou menos idênticos em termos de habilitações literárias, situação que pode ser explicada pelo facto do grupo de calibragem ser um grupo mais jovem e por isso a grande maioria ainda não ter concluído a sua formação.

Por último, em termos de rendimentos, a maioria $(69,2 \%)$ dos indivíduos do grupo de calibragem tem rendimentos até $549 €$ mensais brutos e cerca de $20 \%$ apresentam rendimentos que variam entre $550 €$ e $990 €$, o que significa que apenas uma reduzida parte da $\operatorname{amostra}(10,1 \%)$ aufere rendimentos mensais superiores a $1000 €$.

Em relação ao grupo experimental da âncora alta (questionário n. ${ }^{2}$ ), cerca de $46 \%$ do grupo aufere rendimentos médios mensais brutos entre $550 €$ e $999 €$, cerca de $23 \%$ auferem entre $1000 €$ e $1499 €$ mensais, cerca de $20 \%$ até $549 €$ e minorias deste grupo $(5,33 \%$ e $4,73 \%$ respetivamente) auferem rendimentos mensais entre $1500 €$ e $2000 €$ e mais de $2000 €$.

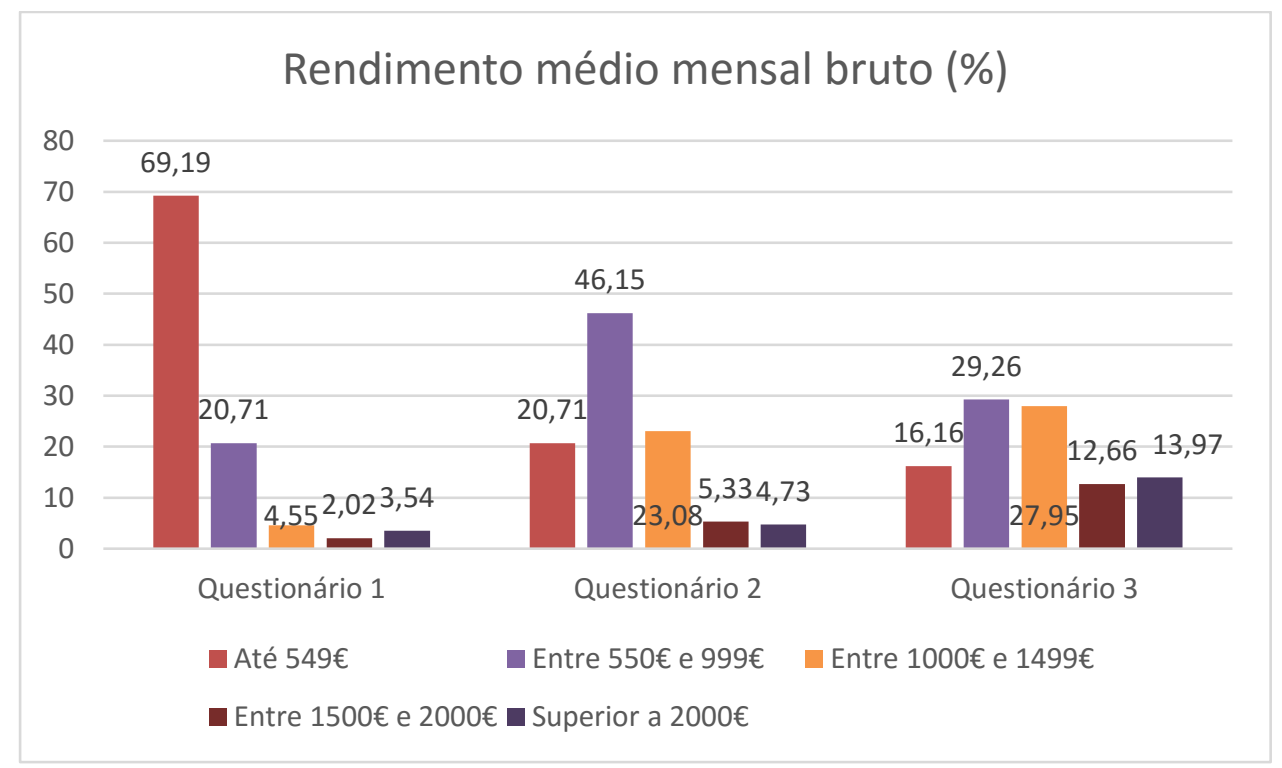

Gráfico 4: Rendimento dos inquiridos

O grupo experimental da âncora baixa (questionário n.ำ), apresenta de uma forma geral indivíduos com rendimentos mais elevados, com cerca de $29 \%$ a auferir mensalmente entre $550 €$ e $999 €$ e cerca de $28 \%$ a auferir entre $1000 €$ e $1499 €$ mensais. A categoria dos indivíduos com remunerações até $549 €$ mensais apresenta neste questionário a 
percentagem mais reduzida $(16,16 \%)$ de entre os três questionários e mais de $26 \%$ deste grupo aufere mais de $1500 €$ mensais.

Em termos gerais, verifica-se que o grupo de calibragem é aquele que apresenta remunerações mais baixas, o grupo experimental da âncora baixa apresenta remunerações mais elevadas, estando o grupo experimental da âncora alta numa situação intermediária.

\subsubsection{Preocupações Ambientais dos Inquiridos}

No primeiro grupo de perguntas do questionário era solicitado aos indivíduos que se autoavaliassem numa escala de 1 a 5 , onde 1 corresponde a nunca, 2 a raramente, 3 a às vezes, 4 a frequentemente e 5 a sempre, relativamente a alguns comportamentos associados às preocupações ambientais.

Ao questionar os indivíduos relativamente à frequência com que fazem a reciclagem, em termos gerais é possível afirmar que os grupos experimentais têm uma maior preocupação em separar os lixos do que o grupo de calibragem, uma vez que, nos grupos experimentais mais de 50\% de cada grupo afirma reciclar sempre ou com frequência. A percentagem dos indivíduos que afirma nunca reciclar é também superior no grupo de calibragem, onde representa cerca de $11 \%$ dos indivíduos, comparativamente com os $6 \%$ e $8 \%$ do grupo experimental da âncora alta e da âncora baixa, respetivamente.

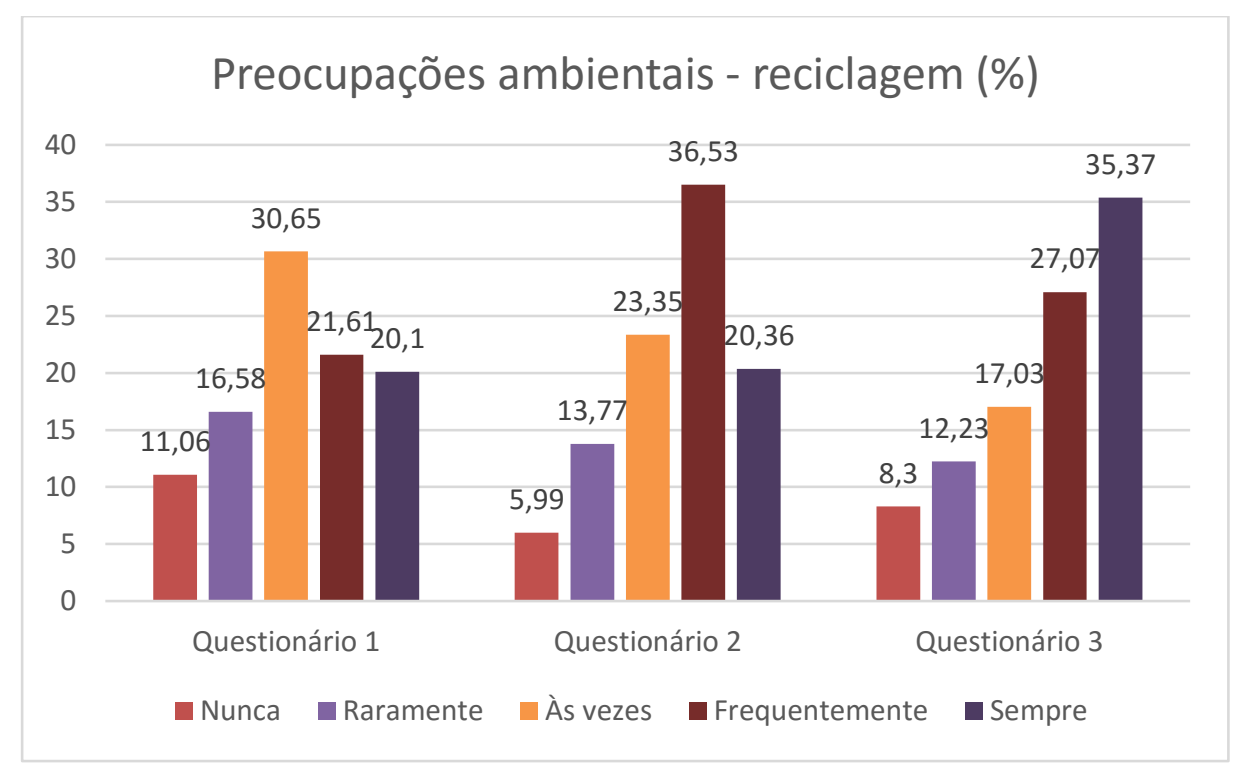

Gráfico 5: Hábito de separação dos lixos dos inquiridos 
Quando questionados relativamente ao hábito de encher por completo as máquinas de lavar antes de as por a trabalhar, a maioria dos indivíduos inquiridos que respondeu aos três questionários afirma encher sempre as máquinas (57,79\% no questionário n. ${ }^{\circ} 1,56,29 \%$ no questionário n. ${ }^{2} 2$ e 59,83\% no questionário n. 3).

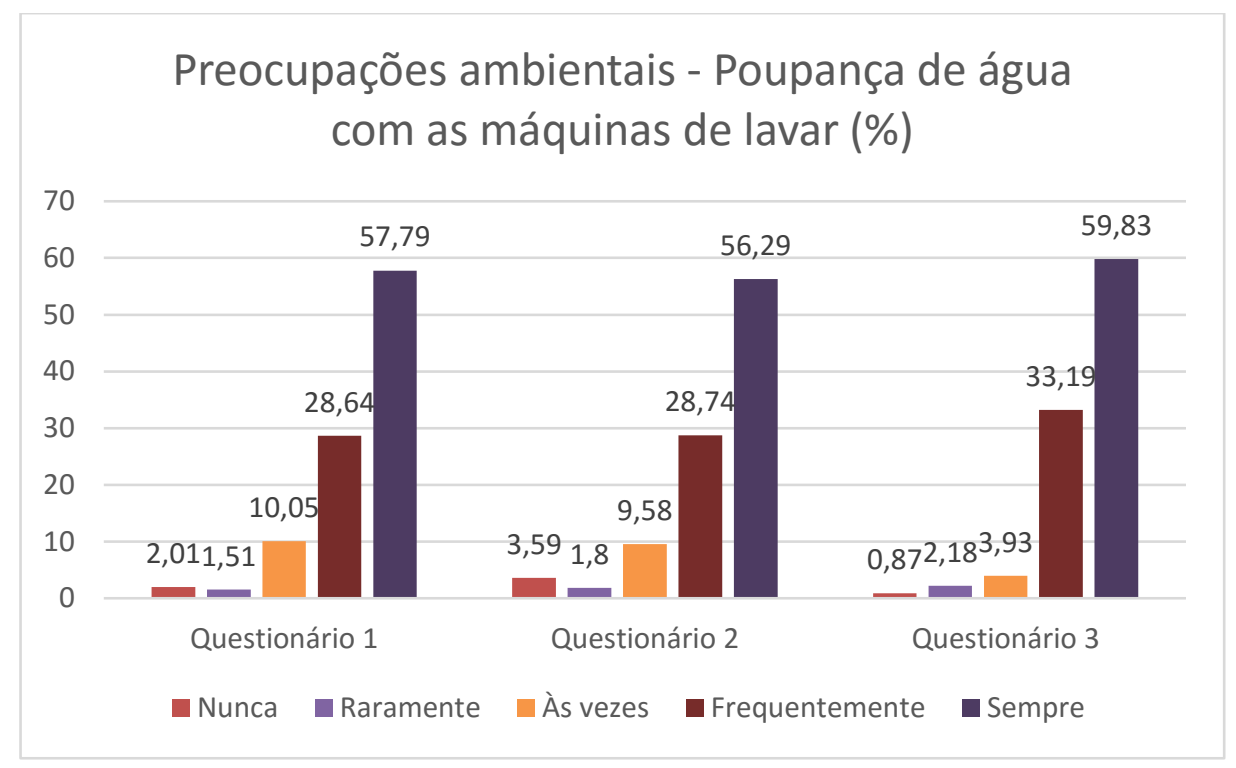

Gráfico 6: Hábito de encher as máquinas de lavar antes de as colocar a funcionar

Em termos de utilização de papel reciclado, nos três questionários é notório que não existe ainda uma grande preocupação por parte dos indivíduos em comprar este tipo de papel. Mais de metade dos inquiridos, em cada um dos questionários, afirma que nunca ou raramente compra papel reciclado. 


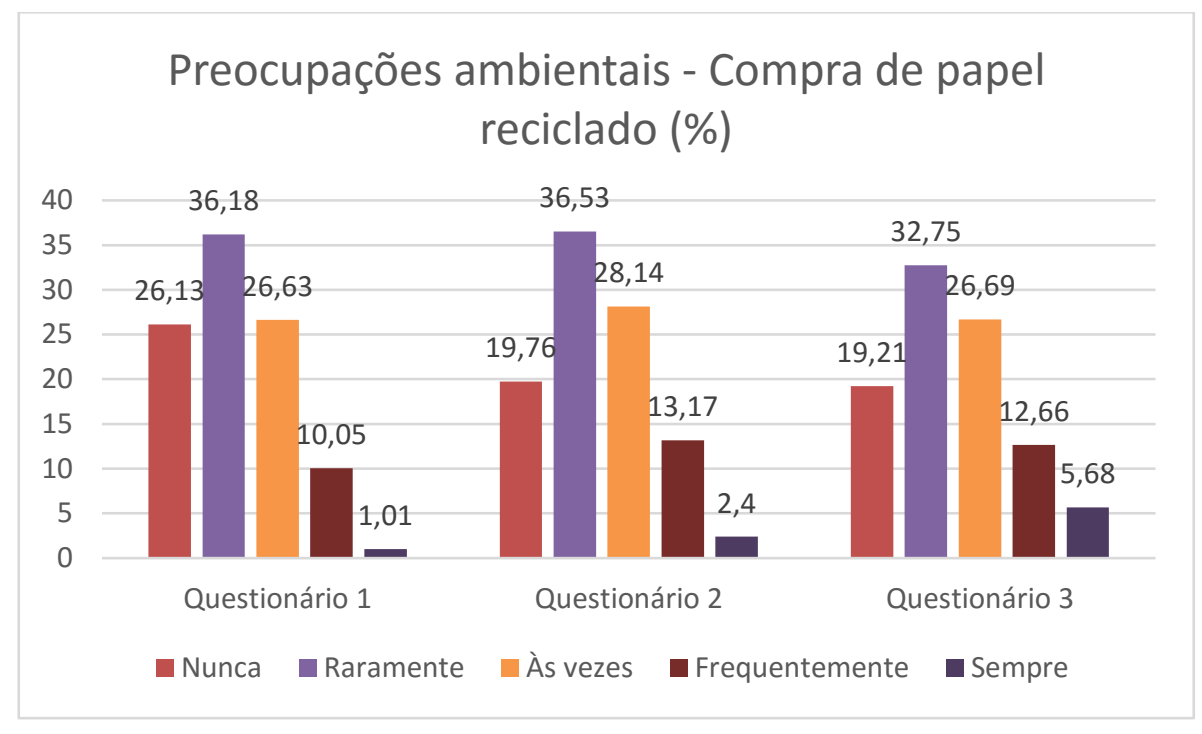

Gráfico 7: Hábito de compra de papel reciclado dos inquiridos

A percentagem dos indivíduos que afirma comprar sempre este tipo de papel, é também bastante reduzida nos três questionários, correspondendo a cerca de $1 \%$ do grupo de calibragem (questionário n. ${ }^{\circ}$ ), cerca de $2 \%$ no grupo experimental da âncora alta (questionário n. ${ }^{\circ}$ ) e a menos de $6 \%$ no caso do grupo experimental da âncora baixa (questionário n. ${ }^{3}$ ).

Uma outra questão, pretendia perceber o grau de preocupação dos inquiridos com o meio ambiente, nomeadamente perceber o seu hábito de reutilizar sacos de plástico. Nesta questão, ficou evidenciada uma clara preocupação por parte dos indivíduos em executar esta prática no seu dia-a-dia.

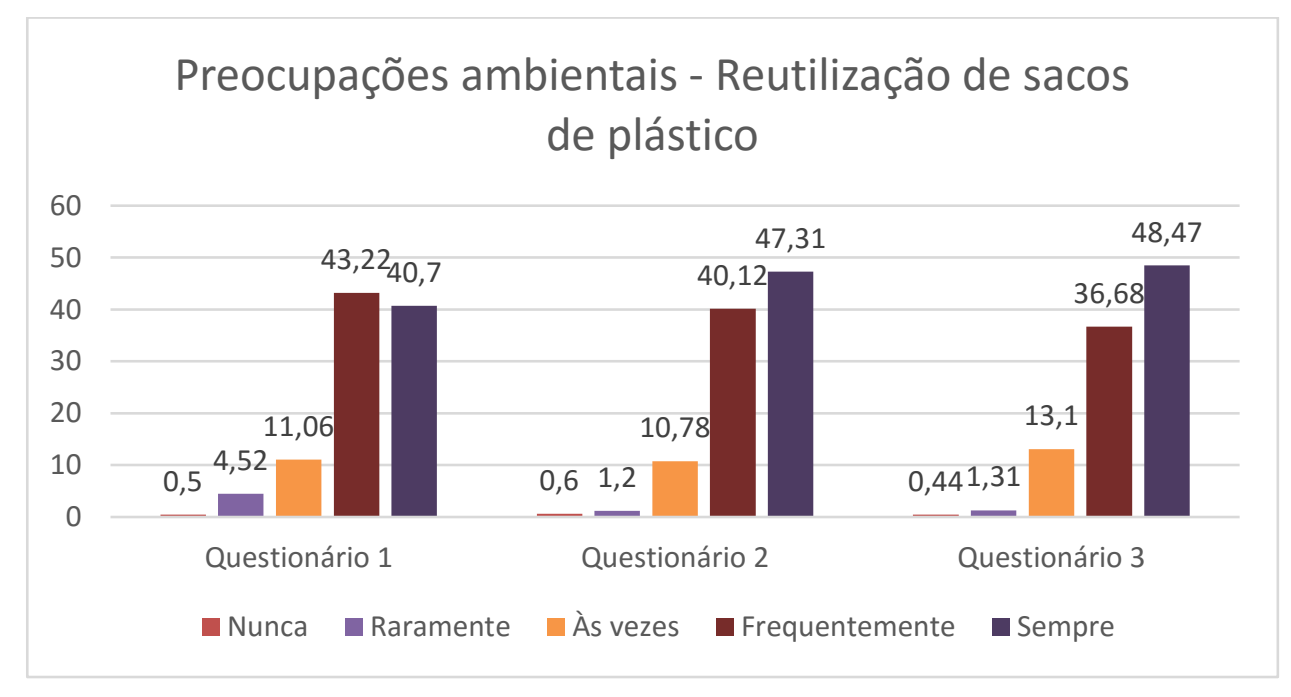

Gráfico 8: Hábito de reutilização de sacos de plástico dos inquiridos 
Mais de $80 \%$ dos indivíduos inquiridos em cada um dos questionários, afirmou reutilizar sempre ou com frequência os sacos de plástico. Nos três questionários distintos, as respostas a esta questão revelaram-se bastante idênticas, com as pessoas que afirmam reutilizar sacos de plástico às vezes, a corresponder a aproximadamente $10 \%$ de cada um dos grupos e as pessoas que afirmam que raramente ou nunca reutilizam sacos de plástico a não exceder os $6 \%$ em cada um dos grupos.

Quando questionados sobre a frequência com que utilizam lâmpadas de baixo consumo, mais de $65 \%$ dos inquiridos nos questionários n. ${ }^{\circ} 1, n .^{\circ} 2$ e n. 3 afirmam utilizar sempre ou com frequência este tipo de lâmpadas.

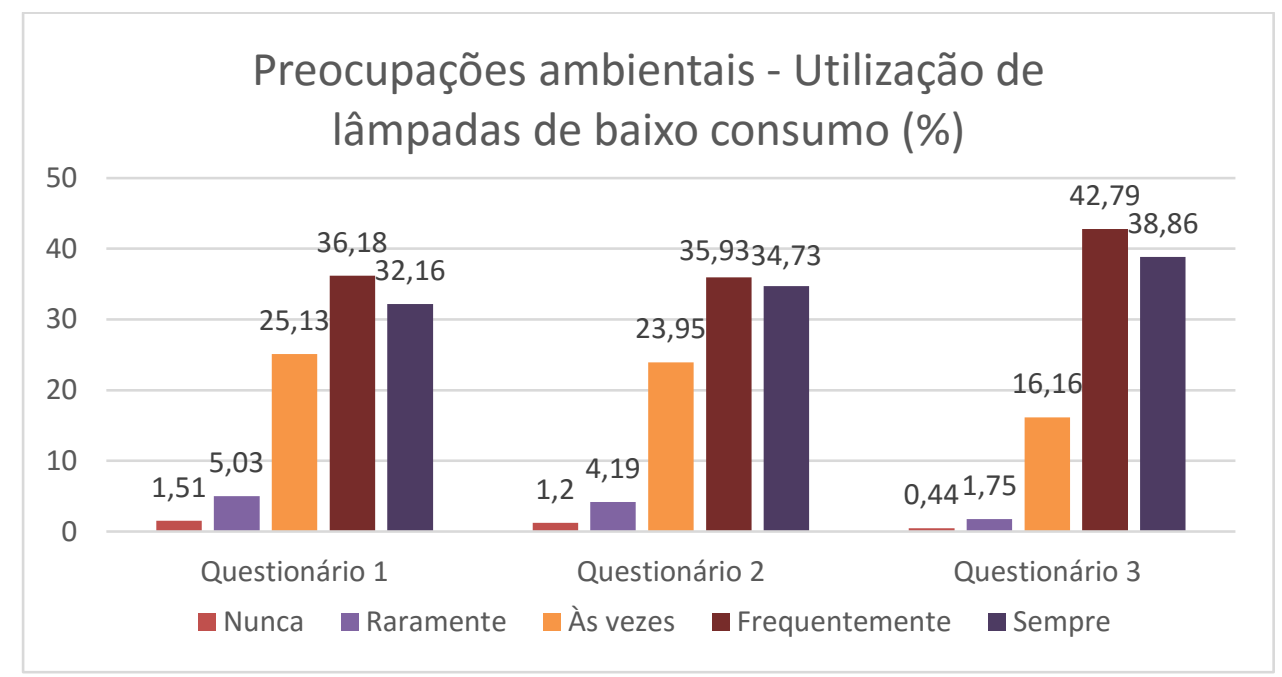

Gráfico 9: Utilização de lâmpadas de baixo consumo por parte dos inquiridos 
Por fim, relativamente à utilização de produtos com rótulo ecológico, a maioria dos indivíduos inquiridos $(51,76 \%)$ do grupo de calibragem, afirmam que às vezes utilizam este tipo de produtos. No caso do grupo experimental da âncora alta (questionário n. ${ }^{\circ 2}$ ), a maioria $(47,9 \%)$ admite utilizar apenas às vezes este tipo de produto. No caso do grupo experimental da âncora baixa, a situação é semelhante, com 46,29\% dos inquiridos a indicar comprar por vezes produtos com rótulo ecológico.

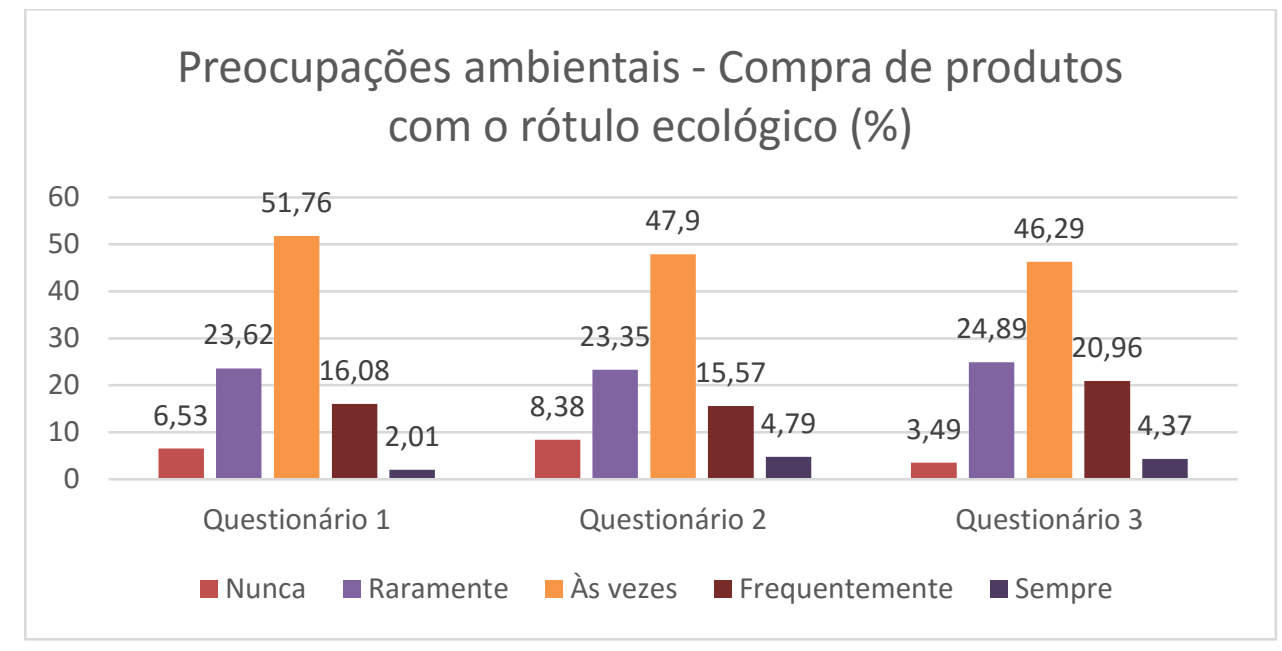

Gráfico 10: Hábito de compra de produtos com o rótulo ecológico dos inquiridos

Considerando este conjunto de perguntas, em termos globais, é possível considerar que os indivíduos dos três grupos da amostra demonstram ter preocupações ambientais, refletindo assim, essas preocupações na prática dos comportamentos acima referidos. Conforme foi possível constatar, não se verificam grandes diferenças no grau de preocupação com as questões ambientais entre os três grupos distintos.

Tendo em conta que a maioria dos inquiridos tem idades até aos 45 anos de idade, pode concluir-se que esta geração já valoriza consideravelmente o meio ambiente, seja pela educação paternal, seja pelo curriculum académico ou outra situação. Verifica-se que esta é de facto, uma geração que compreende e pratica de uma forma natural comportamentos associados às preocupações ambientais.

Apesar disso, torna-se importante esclarecer que muitos destes comportamentos associados às preocupações ambientais permitem também, quando executados, que as famílias poupem dinheiro (é o caso da questão sobre o hábito de encher as máquinas de lavar sempre antes de as colocar a funcionar e o caso da reutilização de sacos de plástico). Por isso, os indivíduos que as executam, podem não estar propriamente preocupados com o meio ambiente mas apenas com a redução de custos. $O$ facto da grande parte dos 
indivíduos reutilizar os sacos de plástico pode estar relacionado com a recente medida política que obriga a que seja cobrado um valor por cada saco de plástico nos supermercados.

Por outro lado, a menor utilização de papel reciclado e a compra de produtos com o rótulo ecológico pode não querer significar exatamente falta de preocupação ambiental mas dever-se ao facto de se tratarem de produtos mais dispendiosos. Esta justificação pode explicar também a grande concentração de respostas "às vezes", verificada quando se questionou aos inquiridos se compravam produtos com o rótulo ecológico.

Em termos de reciclagem, como já foi dito anteriormente, é possível verificar que os grupos experimentais apresentam níveis de frequência de separação dos resíduos domésticos superiores ao grupo de calibragem. 


\section{Apresentação e discussão dos resultados}

O capítulo atual, apresenta os resultados obtidos através dos dados recolhidos com base nos questionários, testando o efeito de ancoragem conforme indicado no capítulo anterior. Para processamento e obtenção destes resultados foram utilizados o software SPSS (Statistical Package for Social Sciences), versão 23 para Windows e ainda a ferramenta excel 2013.

Numa primeira secção, são apresentados os resultados relativos ao grau de aceitação de um incentivo económico para a reciclagem por parte dos inquiridos. Depois é apresentado, numa segunda secção, o cálculo e a obtenção dos valores que foram utilizados como âncoras. Por fim, apresentam-se os índices do efeito ancoragem obtidos.

\subsection{Reciclagem com Incentivo Económico}

Todos os indivíduos da amostra foram inquiridos em relação à sua possível prática da reciclagem caso existisse um incentivo económico associado a esse comportamento, sendo esta pergunta igual nos três questionários realizados ("Estaria disposto a reciclar sempre o plástico/vidro/papel se a essa prática estivesse associada uma recompensa monetária?”).

No caso do plástico, é possível verificar que os três grupos apresentam resultados relativamente semelhantes, sendo as respostas "sim" ou "já reciclo sem recompensa", aquelas que mais se verificam.

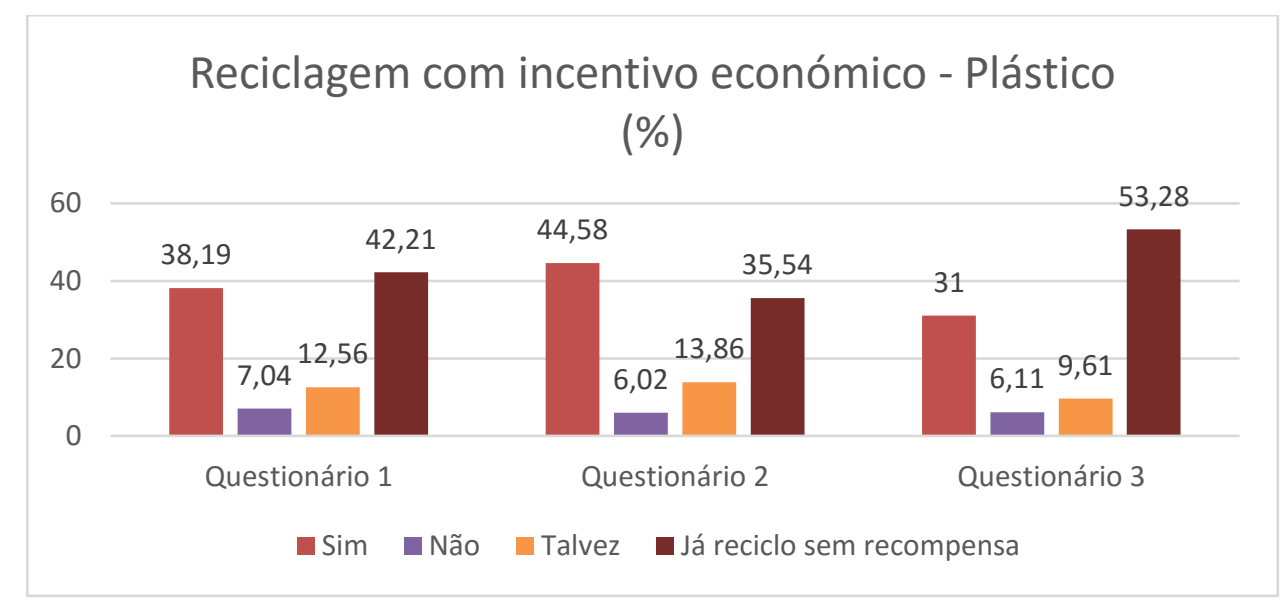

Gráfico 11: Reciclagem com incentivo económico no caso do plástico 
No grupo de calibragem (questionário n. ${ }^{\circ}$ ), mais de $40 \%$ dos inquiridos afirmam já reciclar sem recompensa, cerca de $38 \%$ admite que reciclaria sempre o plástico se existisse um incentivo económico. Relativamente ao grupo experimental da âncora alta (questionário n. ${ }^{\circ}$ ), verifica-se que quase $45 \%$ dos inquiridos assume que reciclaria sempre o plástico caso estivesse um incentivo económico associado a esta prática e cerca de $35 \%$ afirmam que já o faz sem recompensa. Por fim, em relação ao grupo experimental da âncora baixa, 53,28\% do grupo afirma já fazer a reciclagem do plástico sem incentivo económico, $31 \%$ admite que o faria se o mesmo existisse.

Em relação ao material vidro, quando questionados acerca de um possível incentivo económico para a reciclagem, no grupo de calibragem, 47,24\% dos inquiridos afirmou já reciclar sem recompensa, enquanto cerca de $38 \%$ faria a reciclagem do vidro se estivesse uma recompensa associada. No grupo experimental da âncora alta, cerca de $41 \%$ dos inquiridos diz que faria a reciclagem do vidro caso existisse uma recompensa associada, enquanto cerca de $40 \%$ afirmam que já o faz sem recompensa. Por fim, no grupo experimental da âncora baixa (questionário n.3), 53,28\% dos inquiridos afirma já fazer a reciclagem do vidro sem incentivo económico associado e cerca de $33 \%$ diz que o faria se o mesmo existisse.

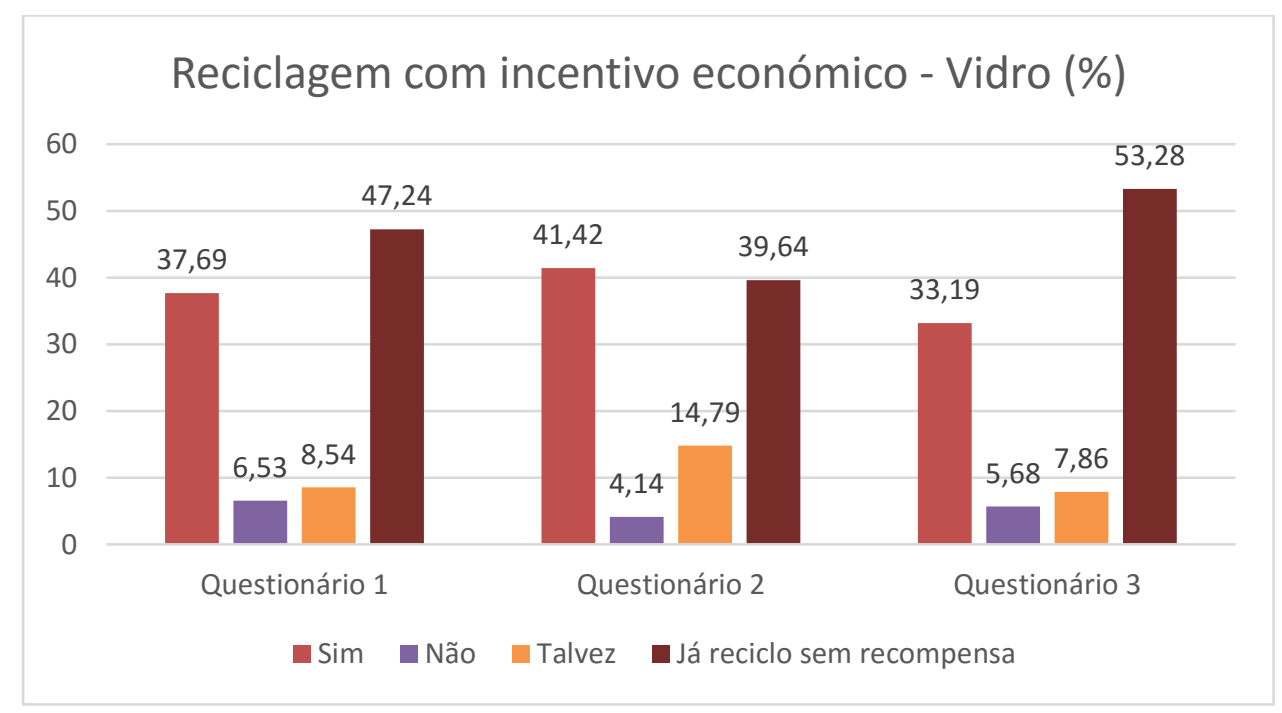

Gráfico 12: Reciclagem com incentivo económico no caso do vidro 
Em relação à reciclagem do papel, quando questionados os indivíduos do grupo de calibragem, 45,73\% afirmaram já fazer a reciclagem do papel sem recompensa contra cerca de $38 \%$ que afirmam que a fariam caso existisse uma recompensa associada. No grupo experimental da âncora alta (questionário n. ${ }^{2}$ ), 43,79\% dos inquiridos diz que faria esta separação caso existisse um incentivo económico associado e cerca de $36 \%$ dizem que já o faz sem esse incentivo. No que diz respeito ao grupo experimental da âncora baixa (questionário n.3), quase 53\% dos inquiridos admite já fazer a reciclagem do papel sem incentivo económico associado, contra cerca de $33 \%$ que afirmam que o faria se o mesmo existisse.

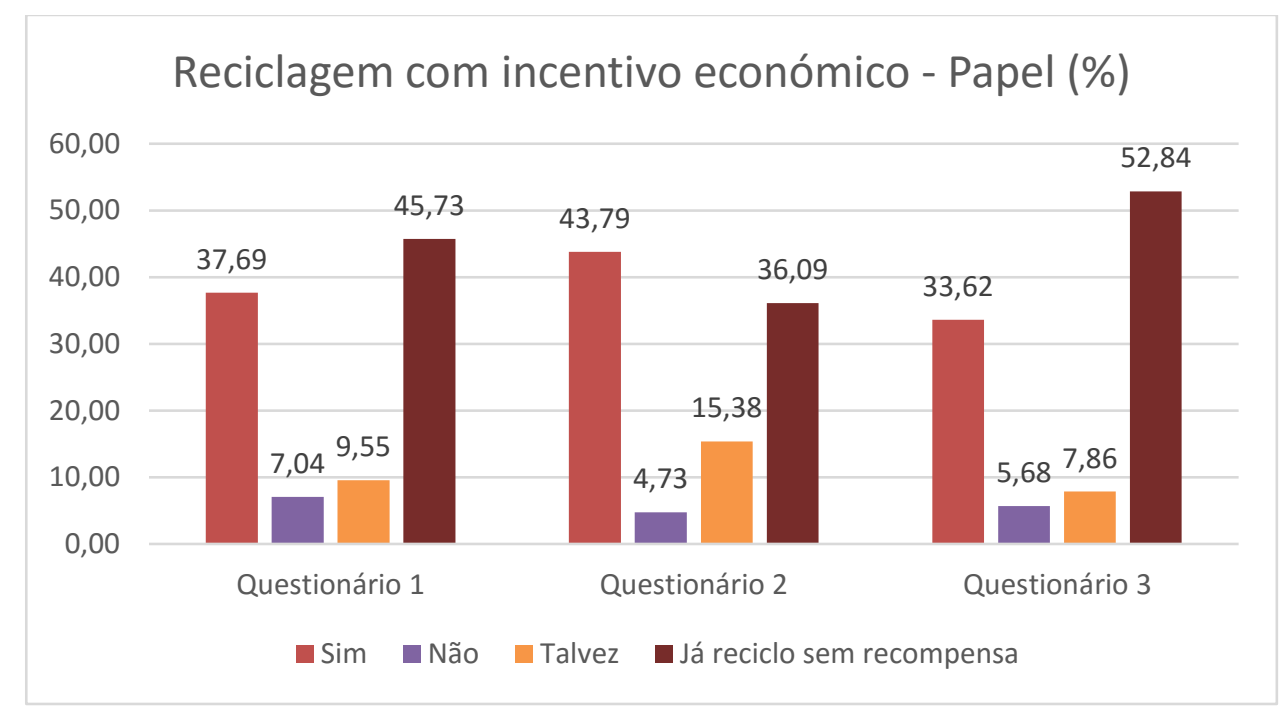

Gráfico 13: Reciclagem com incentivo económico no caso do papel

Em termos gerais é possível verificar que as respostas dadas pelos três grupos são bastante idênticas.

\subsection{Valores âncora}

Para estabelecer os valores âncora para os questionários dos grupos experimentais, foram utilizados os valores estabelecidos pelo grupo de calibragem relativos ao seu valor de WTA para a prática da reciclagem.

Aos 101 indivíduos inquiridos no grupo de calibragem que afirmaram que passariam a fazer sempre a reciclagem do plástico, do vidro ou do papel, ou que talvez passassem a 
fazer sempre a reciclagem do plástico, do vidro ou do papel caso se a esta estivesse associado um incentivo monetário. Assim, foi perguntado qual seria então o seu valor de WTA para a essa prática ("Qual o valor em euros, que necessitaria de receber de modo a separar $1 \mathrm{~kg}$ de plástico/vidro/papel?”).

Os resultados apontam para uma média de $11,05 €$ por quilo de plástico reciclado, um valor mínimo de $0,03 €$ e um valor máximo de $200 €$.

Para uma análise mais correta dos dados, foram retirados os dados que representavam valores "outliers" ou seja valores extremos (extremamente altos) que poderiam influenciar os valores dos percentis e, consequentemente, os valores que iriam servir como valores âncora para os próximos questionários. Assim, em termos de percentis destes valores foram obtidos os seguintes resultados:

Tabela 1: Percentis WTA do plástico

\begin{tabular}{|c|c|c|c|c|c|c|c|}
\hline \multirow{3}{*}{ WTA Plástico } & \multicolumn{8}{|c|}{ Percentis } \\
\cline { 2 - 8 } & $\mathbf{5}$ & $\mathbf{1 0}$ & $\mathbf{2 5}$ & $\mathbf{5 0}$ & $\mathbf{7 5}$ & $\mathbf{9 0}$ & $\mathbf{9 5}$ \\
\cline { 2 - 8 } & 0,0740 & 0,4000 & 0,8000 & 1,5000 & 5,0000 & 10,0000 & 11,0000 \\
\hline
\end{tabular}

Sendo os valores âncora gerados a partir dos percentis do grupo de calibragem (Jacowitz \& Kahneman, 1995), e tendo em conta os percentis automaticamente disponibilizados pelo software SPSS, para os questionários 2 e 3 foram assumidos o valor do percentil 25 como âncora baixa e o valor do percentil 90 como âncora alta. Podemos assim afirmar que no presente estudo, para o WTA do plástico, a âncora baixa corresponderá a $0,80 € / \mathrm{KG}$ e a âncora alta a $10 € / \mathrm{KG}$.

No caso do vidro, 92 indivíduos apontam valores de WTA para a prática da reciclagem e que se traduzem numa média de 9,1762€ por quilo de vidro reciclado, um valor mínimo de $0,02 €$ e valor máximo de $200 €$. Mais uma vez, foram retirados os valores "outliers" e posteriormente calculados os percentis:

Tabela 2: Percentis WTA do vidro

\begin{tabular}{|c|c|c|c|c|c|c|c|}
\hline \multirow{3}{*}{ WTA Vidro } & \multicolumn{10}{|c|}{ Percentis } \\
\cline { 2 - 8 } & $\mathbf{5}$ & $\mathbf{1 0}$ & $\mathbf{2 5}$ & $\mathbf{5 0}$ & $\mathbf{7 5}$ & $\mathbf{9 0}$ & $\mathbf{9 5}$ \\
\cline { 2 - 8 } & 0,0500 & 0,1000 & 0,5000 & 1,0000 & 5,0000 & 8,0000 & 10,0000 \\
\hline
\end{tabular}


Com base nos resultados apresentados na tabela acima para o WTA do vidro, o valor da âncora baixa foi fixado em $0,50 € / \mathrm{KG}$ e o valor da âncora alta em $8 € / \mathrm{KG}$.

Para a reciclagem do papel, 94 indivíduos da amostra apontaram valores de WTA para reciclar que se traduzem numa média de $17,18 €$ por quilo, um valor mínimo de $0,05 €$ e um valor máximo de $800 €$. Adotando o mesmo procedimento que anteriormente, depois de retirados os dados que representavam valores "outliers foram obtidos os seguintes percentis:

Tabela 3: Percentis WTA do papel

\begin{tabular}{|c|c|c|c|c|c|c|c|}
\hline \multirow{2}{*}{ WTA Papel } & \multicolumn{9}{|c|}{ Percentis } \\
\cline { 2 - 8 } & $\mathbf{5}$ & $\mathbf{1 0}$ & $\mathbf{2 5}$ & $\mathbf{5 0}$ & $\mathbf{7 5}$ & $\mathbf{9 0}$ & $\mathbf{9 5}$ \\
\cline { 2 - 8 } & 0,0500 & 0,1000 & 0,5000 & 1,5000 & 5,0000 & 10,0000 & 10,0000 \\
\hline
\end{tabular}

Estes resultados traduzem-se num valor de âncora baixa para o WTA do papel de $0,50 € / \mathrm{KG}$ e $10 € / \mathrm{KG}$ como âncora alta.

Os valores âncora encontrados foram aplicados nos questionários experimentais, colocando uma questão em que se pretendia saber se os inquiridos concordariam com uma medida por parte do governo que obrigasse as empresas de recolha seletiva a pagar estes valores por cada quilo de lixo reciclado:

Questionário n. ${ }^{\circ} 2$ - "Se o governo obrigasse as empresas de recolha seletiva a pagar $10 € / 8 € / 10 €$ (valor da âncora alta) por $\mathrm{kg}$ de plástico/vidro/papel que cada indivíduo reciclasse, concordaria com esta medida?"

Questionário n. ${ }^{\circ}$ - "Se o governo obrigasse as empresas de recolha seletiva a pagar $0,80 € / 0,50 € / 0,50 €$ (valor da âncora baixa) por $\mathrm{kg}$ de plástico/vidro/papel que cada indivíduo reciclasse, concordaria com esta medida?" 
A esta questão, no caso do plástico, $59,72 \%$ dos inquiridos a que foi proposto $0,80 € / \mathrm{kg}$ como valor de WTA, referiu concordar com a proposta enquanto 40,28\% recusaram. Por outro lado, aos indivíduos a quem foi proposto $10 € / \mathrm{kg}$ como valor de WTA para fazerem a reciclagem do plástico, quase $84 \%$ aceitou a proposta e cerca de $16 \%$ recusou.

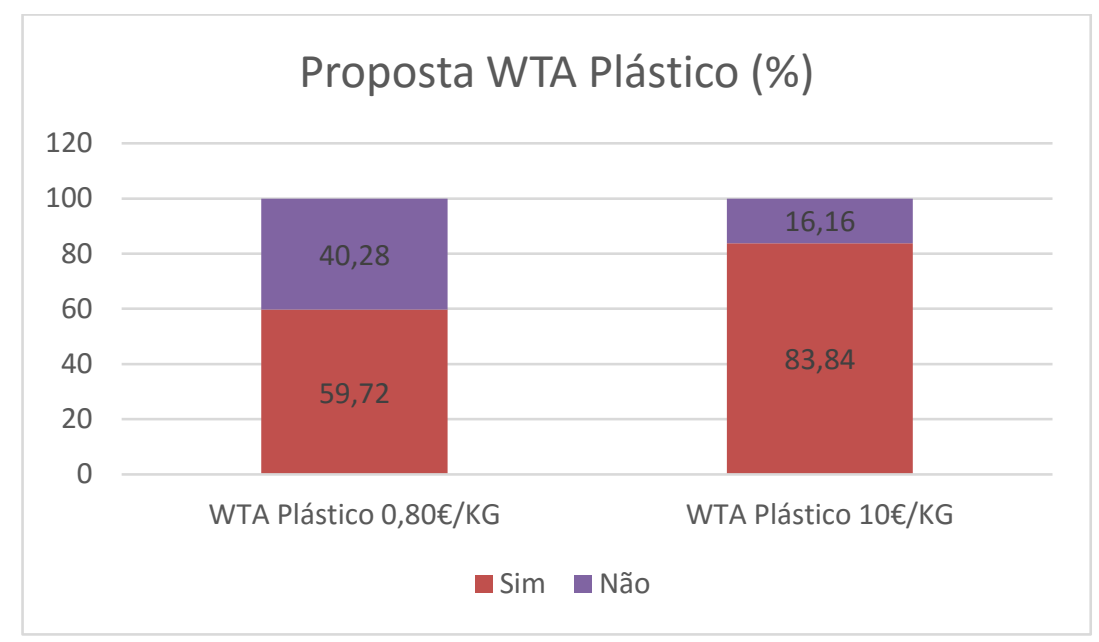

Gráfico 14: Aceitação das propostas do WTA plástico

Em relação à reciclagem do vidro, os inquiridos a quem foi proposta uma recompensa de 50 cêntimos por cada quilo, cerca de $60 \%$ concordou com este valor e cerca de $39 \%$ recusou. Aos indivíduos a quem foi proposta a recompensa de 8 euros por quilo, 83,33\% dos inquiridos aceitou a e cerca de $16 \%$ recusou.

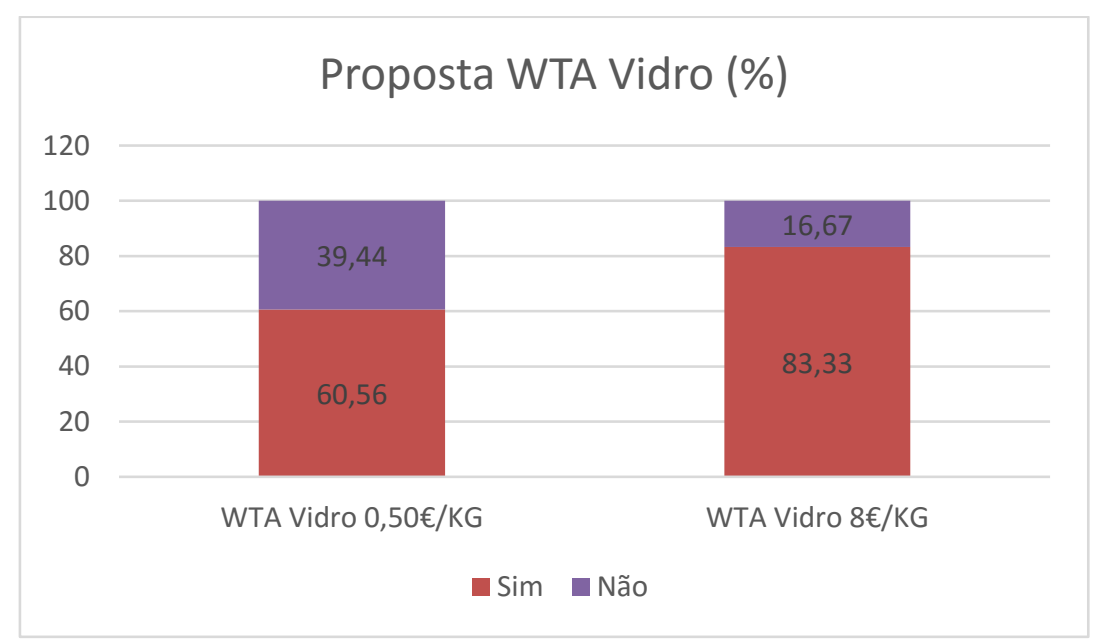

Gráfico 15: Aceitação das propostas de WTA do vidro 
Por fim, em relação à reciclagem do papel, quando proposto um valor de WTA de 50 cêntimos por quilo, cerca de $59 \%$ dos inquiridos referem que aceitaria a proposta enquanto cerca de $40 \%$ recusou. Quando proposto um valor de WTA de 10 euros por quilo de papel reciclado, $84 \%$ dos inquiridos aceitou a proposta enquanto apenas $16 \%$ recusaram.

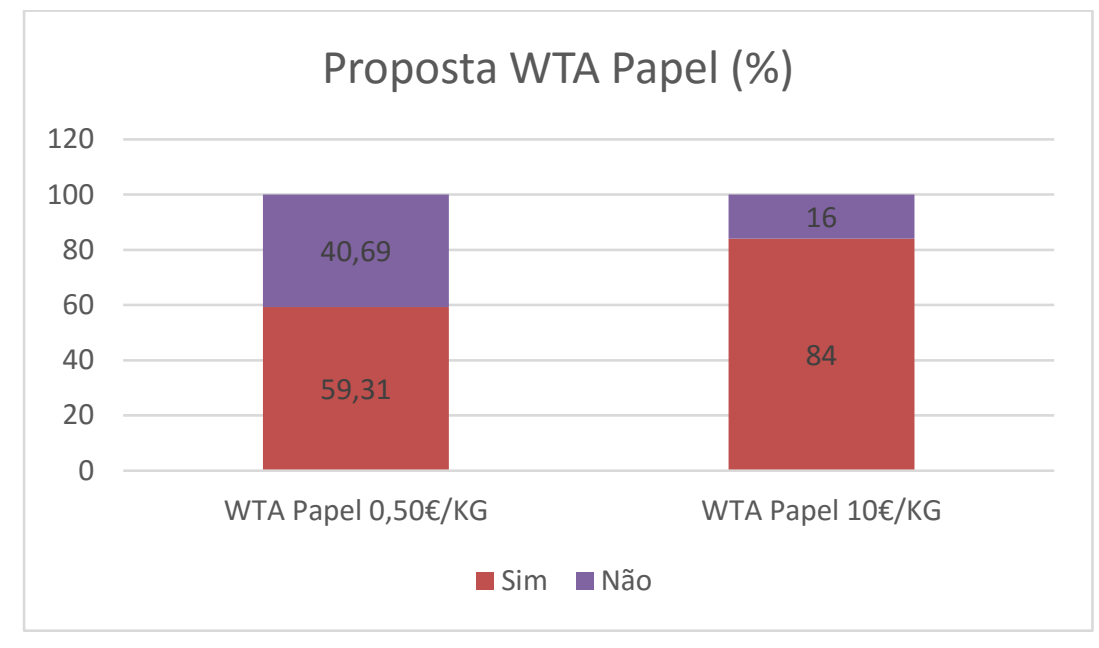

Gráfico 16: Aceitação das propostas de WTA do papel

\subsection{Efeito ancoragem}

Nesta secção são apresentados os resultados dos testes estatísticos ao valor das medianas dos três questionários e analisados os índices de ancoragem com base nos dados obtidos através da realização dos questionários.

\subsubsection{Testes estatísticos e índices de ancoragem}

Para comparação das medianas do valor de WTA entre os três questionários distintos e para cada um dos três materiais realizou-se o teste Kruskal-Wallis, tendo em conta a rejeição da hipótese de normalidade dos dados, para um nível de significância de 5\%, verificada através do teste de Kolmogorov-Smirnov. Realizado o teste Kruskal-Wallis, obteve-se um p-value de 0,00 para os três materiais, pelo que se rejeita a hipótese de igualdade das medianas, isto é, as medianas do valor de WTA são significativamente diferentes entre os três questionários e para cada tipo de material. 
Constatada esta diferença, analisou-se de seguida o eventual impacto das âncoras introduzidas através do cálculo dos índices de ancoragem (IA) desenvolvidos por Jacowitz \& Kahneman (1995), que utilizam as medianas do grupo de calibragem e do grupo experimental bem como os valores âncora, conforme descrito no capítulo anterior. Assim, foram obtidos os índices seguintes:

Tabela 4: Índices de ancoragem obtidos

\begin{tabular}{|c|c|c|c|}
\cline { 2 - 4 } \multicolumn{1}{c|}{} & Plástico & Vidro & Papel \\
\hline IA (âncora alta) & 0,375 & 0,539 & 0,375 \\
\hline IA (âncora baixa) & 0,833 & 1,000 & 0,667 \\
\hline IA (geral) & 0,435 & 0,600 & 0,421 \\
\hline
\end{tabular}

No caso da âncora alta, em relação à reciclagem do plástico, perante o índice apresentado, é possível verificar que a mediana do grupo experimental se moveu cerca de $37 \%$ em direção à âncora de valor $10 €$, revelando assim que o efeito ancoragem não é assim tão significativo no caso desta pergunta. Já em relação à reciclagem do vidro, foi possível concluir que a mediana do grupo experimental se moveu cerca de $50 \%$ em direção à âncora, ou seja, verifica-se o efeito ancoragem. Por seu lado, relativamente à reciclagem do papel, e com base no resultado obtido, verifica-se que a mediana do grupo experimental se moveu cerca de $37 \%$ em direção à âncora o que, tal como no caso do plástico, não evidencia de forma significativa o efeito ancoragem.

Relativamente à âncora baixa, em relação à reciclagem do plástico, o índice obtido permite concluir que a mediana do grupo experimental se moveu mais que $80 \%$ em direção à âncora, o que significa que estamos perante o efeito ancoragem. Já em relação à reciclagem do vidro, o índice de ancoragem obtido, de $100 \%$, permite concluir que a mediana do grupo experimental se moveu completamente em direção à âncora, indiciando, portanto, um claríssimo efeito de ancoragem. Por fim, naquilo que diz respeito à reciclagem do papel, o índice obtido traduz que a mediana do grupo experimental se moveu mais de $65 \%$ em direção à âncora, o que revela também a existência do efeito ancoragem, ainda que se verifique de uma forma mais ténue do que nos dois casos anteriores. 
Em termos gerais, relativamente à reciclagem do plástico obteve-se um índice de ancoragem de 0,43. Com este valor é possível verificar que a mediana do grupo experimental se moveu cerca de $40 \%$ em direção ao valor da âncora. Em relação à reciclagem do vidro, verificou-se que a mediana se moveu $60 \%$ em direção à âncora, correspondendo assim a um grau de efeito ancoragem traduzido num valor de 0,6 numa escala de 0 a 1. Por fim, em relação à reciclagem do papel, a mediana do grupo experimental moveu-se cerca de $42 \%$ em direção à âncora, o que significa que estamos perante um efeito ancoragem traduzido num valor de 0,42 numa escala de 0 a 1 .

Segundo Jacowitz \& Kahneman (1995), quanto maior é este índice de ancoragem maior é a afetação da heurística da ancoragem na tomada de decisão do indivíduo. Assim, verifica-se que os valores apresentados pelo grupo experimental da âncora baixa foram claramente mais influenciados pela âncora apresentada do que os valores apresentados pelo grupo experimental da âncora baixa.

Adicionalmente, por forma a perceber se os índices de ancoragem variavam muito consoante o sexo dos inquiridos, estes foram calculados de forma separada para o sexo feminino e para o sexo masculino.

Tabela 5: Índices de ancoragem obtidos por sexo

\begin{tabular}{|c|c|c|c|c|}
\cline { 2 - 5 } \multicolumn{1}{c|}{} & & Plástico & Vidro & Papel \\
\hline \multirow{3}{*}{ IA (âncora alta) } & Feminino & 0,375 & 0,500 & 0,375 \\
\cline { 2 - 5 } & Masculino & 0,375 & 0,571 & 0,375 \\
\hline \multirow{2}{*}{$\begin{array}{c}\text { IA (âncora } \\
\text { baixa) }\end{array}$} & Feminino & 0,833 & 1,000 & 0,800 \\
\cline { 2 - 5 } & Masculino & 0,833 & 0,400 & 1,000 \\
\hline \multirow{2}{*}{\begin{tabular}{c} 
IA (geral) \\
\cline { 2 - 5 }
\end{tabular}} & Feminino & 0,435 & 0,600 & 0,442 \\
\cline { 2 - 5 } & Masculino & 0,435 & 0,560 & 0,474 \\
\hline
\end{tabular}

Como se pode constatar na tabela acima, não se verificaram grandes diferenças entre o índice de ancoragem por sexos, exceto no grupo do questionário da âncora baixa 
(questionário n. ${ }^{\circ}$ ), no caso do material vidro, em que o índice de ancoragem das mulheres inquiridas é de $100 \%$ enquanto o dos homens é de $40 \%$. Uma vez que, o número de mulheres da amostra é superior ao número de homens, então isto pode querer dizer que o facto de as mulheres terem sido mais influenciadas pelo valor âncora, então, o resultado de $100 \%$ do índice de ancoragem para o material vidro no caso da âncora baixa, pode ter sido causado pelas mulheres.

\subsubsection{Discussão dos resultados}

Conforme verificado na secção anterior, o material que se destaca em termos de índice de ancoragem é o vidro, uma vez que os valores apontados para reciclar o mesmo pelos indivíduos são os mais influenciados de entre os três materiais. De destacar ainda que no caso do grupo experimental da âncora baixa, a mediana deste grupo, em relação ao vidro, move-se completamente em direção à âncora que correspondia a 50 cêntimos, sendo obtido um índice de ancoragem de $100 \%$.

Naquilo que diz respeito aos valores dos índices de ancoragem obtidos e ao facto verificado de que a heurística da ancoragem influenciou mais os valores apresentados pelo grupo experimental da âncora baixa do que os valores apresentados pelo grupo experimental da âncora alta, esta situação pode ser explicada pelo facto de existir uma diferença considerável entre os valores de âncora baixa e os valores da âncora alta. Isto é, perante a situação em que têm que apontar o valor que achariam necessário receber para fazer a reciclagem, os indivíduos sentem dificuldade em apontar um valor. No entanto, conseguem identificar aquilo que acham ser valores demasiado altos e que apesar de os aceitarem, se lhes fossem propostos, continuariam a achá-los elevados. Tomando atenção a alguns comentários deixados pelos inquiridos nos questionários é possível verificar isso mesmo quando, nos questionários do grupo experimental da âncora alta se verificam frases como "demasiado alto" ou "bastaria um valor simbólico" ou ainda "valor muito alto para apenas $1 \mathrm{Kg}$ ".

Para tentar explicar esta situação de "destaque" do material vidro nos índices de ancoragem, talvez possamos refletir sobre as diferenças em termos físicos deste material perante o plástico e o papel. A perceção que o indivíduo tem é que, sendo um material mais pesado, não seria necessário juntar tanto vidro para conseguir um valor que é 
considerado justo, enquanto no papel e no plástico será mais complicado perceber quanto é $1 \mathrm{~kg}$.

É ainda importante destacar que de entre as âncoras altas, o valor âncora atribuído ao vidro é o valor mais baixo ( $8 €$ contra os $10 €$ atribuídos ao plástico e ao papel). Este facto, pode também justificar o índice de ancoragem mais elevado no caso do vidro se partirmos da ideia de que as pessoas consideram que $1 \mathrm{~kg}$ de qualquer um dos materiais é pouco porque nas suas casas produzem vários kgs.

Relativamente ao material papel, que no caso do grupo experimental da âncora baixa que apresentou índices de ancoragem superiores, este apresentou o índice de ancoragem mais baixo dos três materiais, não excedendo 67\%. No grupo experimental da âncora alta, onde os três índices não foram tão elevados, o papel tal como o plástico não chegam aos $40 \%$. Segundo os dados da Sociedade Ponto Verde (2016), em 2015, o material mais reciclado foi o papel, correspondendo a um total de $48 \%$ das retomas, situação esta que é verificada já há alguns anos. O papel é de entre os três materiais, aquele que os portugueses mais reciclam, talvez por isso não sintam a necessidade de receber um incentivo económico para o fazer, por já terem esse hábito.

De destacar ainda que, de entre os três questionários distintos, o questionário número 3, que corresponde ao questionário do grupo experimental da âncora baixa e que, como vimos, foi o mais influenciado pelo valor da âncora. Constitui um grupo onde mais de $62 \%$ dos inquiridos afirma reciclar sempre ou com frequência e onde mais de metade desta amostra afirma já reciclar sem incentivo económico todos os materiais. 


\section{Conclusão}

Com a realização da presente dissertação, foi possível verificar que existe um efeito ancoragem associado a um modelo de avaliação contingente aplicado à prática da reciclagem, tal como Green et al. (1998) defendiam.

Verificou-se, através dos resultados obtidos com a realização do presente estudo, que as medianas dos grupos experimentais se moveram em direção aos valores âncora, com especial ênfase no caso das âncoras baixas. Isto significa que os valores apontados pelos inquiridos como valores necessários de recompensa pela prática constante da reciclagem, foram influenciados pelos valores apresentados nos questionários, em questões anteriores, tal como referiam os estudos desenvolvidos por Jacowitz \& Kahneman (1995) que explicavam a heurística da ancoragem.

Apresentam-se agora, as limitações do estudo e sugestões para futuras investigações.

Uma das melhorias que poderia ser implementada seria procurar obter amostras mais semelhantes para os três questionários. Neste caso, o questionário número 1 tem uma média de idades bastante inferior às médias de idades dos questionários número $2 \mathrm{e}$ número 3 e que pode ter sido o motivo para os valores âncora serem tão díspares.

Outra sugestão, seria a realização do mesmo estudo com uma amostra que permitisse retirar conclusões para uma população, considerando que obter conclusões do estudo para Portugal poderia permitir desbloquear a tomada de medidas políticas ambientais em termos futuros.

Em termos de questionário, poderiam também realizar-se algumas alterações, nomeadamente na questão que pergunta aos inquiridos se estariam dispostos a reciclar sempre se a essa prática estivesse associado um incentivo económico. Nesta questão, poder-se-ia optar por colocar diferentes opções de resposta como "Sim, reciclaria sempre", "Não, não reciclaria sempre mesmo com incentivo", "Talvez reciclasse sempre, se houvesse um incentivo" e "Já reciclo sem recompensa". Esta variedade de respostas poderia trazer mais clareza à questão e ao mesmo tempo poderia também provocar uma maior reflexão sobre a matéria em causa, por parte dos inquiridos.

Para concluir, considero que a realização da presente dissertação de mestrado, se revelou muito importante para a minha formação em gestão, na medida em que me permitiu 
debruçar sobre um tema tão importante como é o meio ambiente e conjugá-lo com um outro tema com o qual a economia comportamental se defronta, como é o efeito ancoragem.

O modelo linear de negócios que tem sido a base da economia em termos mundiais, está nos nossos dias posto em causa por causa da insustentabilidade ambiental que gerou. $\mathrm{O}$ mundo consome muito acima das possibilidades do meio ambiente e não permite que este se regenere, sugerindo a necessidade de uma nova tendência de gestão com base nas preocupações ambientais e de sustentabilidade do meio ambiente.

A transição para uma economia circular que permita que os diferentes materiais sejam reutilizados, recuperados e reciclados é urgente. A reciclagem assume portanto, um papel fundamental para que haja uma garantia de gerações futuras e deve, por isso, ser praticada com maior frequência. A implementação de um sistema PAYT para a reciclagem é uma medida que permitiria um aumento significativo dos níveis de reciclagem no nosso país. $\mathrm{O}$ presente estudo esclarece que no caso da implementação do PAYT, no estabelecimento dos valores a atribuir, utilizando o chamado modelo de avaliação contingente, estará presente o efeito ancoragem. Em termos de gestão pública, a perceção da existência deste tipo de efeito, pode ser utilizada para que se possam utilizar âncoras de interesse. 


\section{Referências bibliográficas}

Agans, R. P., \& Shaffer, L. S. (1994). The Hindsight Bias: The Role of the Availability Heuristic and Perceived Risk. Basic and Applied Social Psychology, 15(4), 439-449. http://doi.org/10.1207/s15324834basp1504_3

Altman, M. (2012). Implications of behavioural economics for financial literacy and public policy. Journal of Socio-Economics, 41(5), 677-690. http://doi.org/10.1016/j.socec.2012.06.002

Aprahamian, F., Chanel, O., \& Luchini, S. (2007). Modeling Starting Point Bias as Unobserved Heterogeneity in Contingent Valuation Surveys: An Application to Air Pollution. American Journal of Agricultural Economics, 89(2), 533-547. http://doi.org/10.1111/j.1467-8276.2006.01020.x

Ariely, D. (2008). Previsivelmente Irracional. (Estrela Polar, Ed.). Lisboa.

Arrow, K., Solow, R., Portney, P. R., Leamer, E. E., Radner, R., \& Schuman, H. (1993). Report of the NOAA Panel on Contingent Valuation. Federal Register, 58(10), 46014614. http://doi.org/10.1258/095646202760029804

Assembleia da República. Re, Resolução da Assempleia da República nº8/2013 (2013). http://doi.org/10.1007/s13398-014-0173-7.2

Barros, G. (2004). Racionalidade E Organizações: Um Estudo Sobre Comportamento Econômico Na Obra De Herbert A. Simon. Universidade de São Paulo.

Batllevell, M., \& Hanf, K. (2008). The fairness of PAYT systems: Some guidelines for decision-makers. Waste Management, 28, 2793-2800. http://doi.org/10.1016/j.wasman.2008.02.031

Boussaidi, R. (2013). Representativeness Heuristic, Investor Sentiment and Overreaction to Accounting Earnings: The Case of the Tunisian Stock Market. In Procedia - Social and Behavioral Sciences (Vol. 81, pp. 9-21). Elsevier B.V. http://doi.org/10.1016/j.sbspro.2013.06.380

Carson, R. T. (2000). Contingent Valuation: A User's Guide. Environmental Science \& Technology, 34, 1413-1418.

Carson, R. T., \& Hanemann, W. M. (2005). Contingent Valuation. In K.-G. Mäler \& J. R. Vincent (Eds.), Handbook of Environmental Economics (Elsevier, Vol. 2, pp. 821936). http://doi.org/10.1016/S1574-0099(05)02017-6

Critcher, C. R., \& Gilovich, T. (2008). Incidental Environmental Anchors. Journal of Behavioral Decision Making, 21, 241-251. http://doi.org/10.1002/bdm

Da Silva, A. A., \& Naldis, V. B. (2012). Incerteza e racionalidade limitada : um estudo empírico no setor financeiro (Vol. 8). São Bernardo do Campo.

Dorow, A., Júnior, J. S. M., Nunes, P., Reina, D., \& Maximiniano, D. R. (2010). A heurística da ancoragem e a tomada de decisão sob risco em investimentos imobiliários. Contabilidade, Gestão E Governança, 13, 86-101. http://doi.org/10.1590/S1984-02922010000900006

Ellen MacArthut Fundation, \& McKinsey \& Company. (2014). Towards the Circular Economy: Accelerating the scale-up across global supply chains. World Economic 
Forum, (January).

Epley, N., \& Gilovich, T. (2006). The anchoring-and-adjustment heuristic: Why the adjustments are insufficient. Psychological Science, 17(4), 311-318. http://doi.org/10.1111/j.1467-9280.2006.01704.x

European Commission. (2014). Towards a circular economy: A zero waste programme for Europe. In Communication from the commission to the European parliament, the council, the european economic and social committee and the committee of the regions. Brussels.

Ferreira, S., \& Marques, R. C. (2015). Contingent valuation method applied to waste management. Resources, Conservation \& Recycling, 99, 111-117. http://doi.org/10.1016/j.resconrec.2015.02.013

Flachaire, E., \& Hollard, G. (2006). Controlling starting-point bias in double-bounded contingent valuation surveys. Land Economics, 82(1992), 103-111. http://doi.org/10.3368/le.82.1.103

Furnham, A., \& Boo, H. C. (2011). A literature review of the anchoring effect. The Journal of Socio-Economics, 40(1), 35-42. http://doi.org/10.1016/j.socec.2010.10.008

Gilovich, T., Griffin, D., \& Kahneman, D. (2002). Heuristics and Biases. Cambridge University Press. http://doi.org/10.5465/AMR.2004.14497675

Global Footprint Network. (2016). Global Footprint Network.

Green, D., Jacowitz, K. E., Kahneman, D., \& Mcfadden, D. (1998). Referendum contingent valuation, anchoring, and willingness to pay for public goods. Resource and Energy Economics, 20, 85-116.

Guo, X., Wong, W. K., Xu, Q., \& Zhu, X. (2015). Production and hedging decisions under regret aversion. Economic Modelling, 51, 153-158. http://doi.org/10.1016/j.econmod.2015.08.007

Hanemann, W. M. (1985). Some Issues in Continuous- and Discrete-Response Contingent Valuation Studies. Northeastern Journal of Agricultural Economics, (1), 5-13.

Herriges, J. A., \& Shogren, J. F. (1996). Starting point bias in dichotomous choice valuation with follow-up questioning. Journal of Environmental Economics and Management, 30(1), 112-131.

Hill, M. M., \& Hill, A. (2000). Investigação por Questionário. (Edições Sílabo, Ed.). Lisboa.

Jacowitz, K. E., \& Kahneman, D. (1995). Measures of Anchoring in Estimation Tasks. Personality and Social Psychology Bulletin, 21(11), 1161-1166.

Junior, J. G. L., \& Mauriz, E. (2011). O efeito da ancoragem gerado pelo modelo de comercio varejista influenciando o processo decisório de compra do consumidor. Seminários Em Administração, 1-17.

Kato, T., \& Hidano, N. (2007). Anchoring effects, survey conditions, and respondents' characteristics: Contingent valuation of uncertain environmental changes. Journal of Risk Research, 10(6), 773-792. http://doi.org/10.1080/13669870701342603

Klayman, J., Soll, J. B., Claudia, G.-V., \& Barlas, S. (1999). Overconfidence: It Depends on How, What, and Whom You Ask. Organizational Behavior and Human Decision 
Processes, 79, 216-247. http://doi.org/http://dx.doi.org/10.1006/obhd.1999.2847

Lobão, J. (2012). Finanças Comportamentais. (Actual, Ed.). Coimbra.

Luo, G. Y. (2012). The Psychological Explanation of Asset Price Overreaction and Underreaction to New Information: Representativeness Heuristic and Conservatism Bias. Journal of Accounting and Finance, 12(2), 38-51.

Luppe, M. R. (2006). A heurística da ancoragem e seus efeitos no julgamento: decisões de consumo. Dissertação de mestrado. Universidade de São Paulo.

Magalhães, S. (2013). Racionalidade Limitada na Tomada de Decisão O efeito de ancoragem na avaliação de Curricula Vitae : um estudo experimental. Universidade do Porto.

Mitchell, R. C., \& Carson, R. T. (1989). Using Surveys To Value Public Goods: the Contingent Valuation Method. (R. for the Future, Ed.). Washington, D.C.

Mussweiler, T., Strack, F., \& Pfeif, T. (2000). Overcoming the Inevitable Anchoring Effect: Considering the Opposite Compensates for Selective Accessibility. Personality and Social Psy, 26, 1142-1150.

Neto, J. C., Filipe, J. A., \& Ramalheiro, B. (2011). Neuromarketing: Consumers and the Anchoring Effect. International Journal of Latest Trends in Finance \& Economic Sciences, 1(4), 183-189.

Nickerson, R. S. (1998). Confirmation bias: A ubiquitous phenomenon in many guises. Review of General Psychology, 2(2), 175-220. http://doi.org/10.1037/10892680.2.2.175

Nofsinger, J. R. (2006). A lógica do mercado: como lucrar com finanças comportamentais. (Fundamento Educacional, Ed.). São Paulo.

Oshikawa, S. (1969). Can Cognitive Dissonance Theory Explain Consumer Behavior? Journal of Marketing, 33, 44-49. http://doi.org/10.2307/1248672

Portney, P. R. (1994). The Contingent Valuation Debate: Why Economists Should Care. Journal of Economic Perspectives, 8(4), 3-17.

Ramiah, V., Xu, X., \& Moosa, I. A. (2015). Neoclassical finance, behavioral finance and noise traders: A review and assessment of the literature. International Review of Financial Analysis, 41, 89-100. http://doi.org/10.1016/j.irfa.2015.05.021

Rodrigues, J. (2013). SISTEMA Pay-As-You-Throw. Universidade do Porto.

Samuelson, W., \& Zeckhauser, R. (1988). Status Quo Bias in Decision Making. Journal of Risk and Uncertainty, 1, 7-59.

Simon, H. A. (1965). Administrative behavior: a study of decision-making processes in administrative organization. (Free Press, Ed.). Michigan.

Simon, H. A. (1994). Behavioural Economics.

Sociedade Ponto Verde. (2016). Sociedade Ponto Verde. Retrieved March 1, 2016, from http://www.pontoverde.pt/

Sousa, M. J., \& Baptista, C. S. (2011). Sociedade Ponto Verde. (1 de Março de 2016). Obtido de http://www.pontoverde.pt Sousa, M. J., \& Baptista, C. S. (2011). Como Fazer Investigação, Dissertações, Teses e Relatórios. (Pactor, Ed.). Lisboa. 
Strack, F., \& Mussweiler, T. (1997). Explaining the Enigmatic Anchoring Effect: Mechanisms of Selective Accessibility. Journal of Personality and Social Psychology, 73(3), 437-446. http://doi.org/10.1037/0022-3514.73.3.437

Thaler, R. H. (1999). Mental Accounting Matters. Journal of Behavioral Decision Making, 12, 183-206. http://doi.org/10.1002/(SICI)1099-0771(199909)12:3<183::AIDBDM318>3.0.CO;2-F

Tronco, P. B., Löbler, M. L., \& Nishi, J. M. (2013). Efeitos da Ancoragem em Julgamentos e Decisões no Mercado Imobiliário: Uma Análise a partir do Nível de Conhecimento dos Decisores (pp. 1-16). IV Encontro de Administração da Informação - ENADI.

Tversky, A., \& Kahneman, D. (1974). Judgment under Uncertainty : Heuristics and Biases. Science, 185(4157), 1124-1131.

Weinstein, N. D. (1987). Unrealistic Optimism About Susceptibility to Health Problems : Conclusions from a Community-Wide Sample. Journal of Behavioral Medicine, 10(5), 481-500.

Wilson, T. D., Houston, C. E., Etling, K. M., \& Brekke, N. (1996). A new look at anchoring effects: basic anchoring and its antecedents. Journal of Experimental Psychology: General, 125(4), 387-402. http://doi.org/10.1037/0096-3445.125.4.387

WWF Portugal. (2016). World Wide Fund for Nature. Retrieved January 20, 2016, from http://www.wwf.pt/ 
Esta página foi intencionalmente deixada em branco 
Anexos 
Anexo I: Questionário nº1 - Grupo de Calibragem

\section{Reciclagem com Incentivo Económico}

O presente questionário surge no âmbito de uma dissertação de mestrado em Gestão da Escola Superior de Tecnologia e Gestão do Instituto Politécnico de Leiria. Agradeço a sua colaboração no preenchimento deste questionário (cerca de 2 minutos), que tem como objetivo reunir informação acerca da prática da reciclagem. É garantida a total confidencialidade e anonimato dos dados recolhidos.

\section{Preocupações Ambientais}

1. Indique, numa escala de 1 a 5 , a frequência com que pratica as ações mencionadas:

1-Nunca 2-Raramente 3-Às vezes 4-Frequentemente 5-Sempre

Efetua a separação dos resíduos domésticos (reciclagem).

Enche sempre a máquina de lavar loiça e roupa antes de as por a funcionar.

Compra papel reciclado.

Reutiliza sacos de plástico.

Utiliza lâmpadas de baixo consumo.

Compra produtos com o rótulo ecológico.

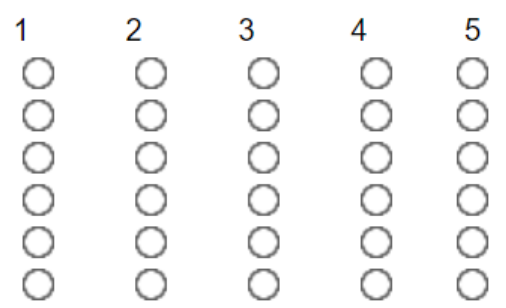

\section{Reciclagem com Incentivo Económico}

2. Estaria disposto a reciclar sempre o plástico se a essa prática estivesse associada uma recompensa monetária? (Caso a sua resposta seja "Não" ou "Já reciclo sem recompensa", passe para a questão 4.)
O Sim
Não
Talvez
Já reciclo sem recompensa

3. Qual o valor em euros, que necessitaria de receber de modo a separar $1 \mathrm{~kg}$ de plástico?

4. Estaria disposto a reciclar sempre o vidro se a essa prática estivesse associada uma recompensa monetária? (Caso a sua resposta seja "Não" ou "Já reciclo sem recompensa", passe para a questão 6.)
O Sim
Não
Talvez
Já reciclo sem recompensa

5. Qual o valor em euros, que necessitaria de receber de modo a separar $1 \mathrm{~kg}$ de vidro?

6. Estaria disposto a reciclar sempre o papel se a essa prática estivesse associada uma recompensa monetária? (Caso a sua resposta seja "Não" ou "Já reciclo sem recompensa", passe para a questão 8 .)
Sim
Não
Talvez
Já reciclo sem recompensa 
7. Qual o valor em euros, que necessitaria de receber de modo a separar $1 \mathrm{~kg}$ de papel?

\section{Perfil do Inquirido}

8. Sexo:

Feminino

Masculino

9. Idade:

10. Habilitações académicas

Ensino Básico (Até ao $9^{\circ} \mathrm{ano}$ )

Ensino Secundário (Até ao $12^{\circ}$ ano)

Licenciatura/Bacharelato

Mestrado

A frequentar Licenciatura/Mestrado

Outro

11. Rendimento médio mensal (bruto)

Até $549 €$

Entre $550 €$ e $999 €$

Entre $1000 €$ e $1499 €$

Entre $1500 €$ e $2000 €$

Superior a $2000 €$

\section{Obrigada pela sua colaboração!}




\section{Anexo II: Questionário n² - Grupo Experimental da Âncora Alta}

\section{$\underline{\text { Reciclagem com Incentivo Económico }}$}

O presente questionário surge no âmbito de uma dissertação de mestrado em Gestão da Escola Superior de Tecnologia e Gestão do Instituto Politécnico de Leiria. Agradeço a sua colaboração no preenchimento deste questionário (cerca de 2 minutos), que tem como objetivo reunir informação acerca da prática da reciclagem. É garantida a total confidencialidade e anonimato dos dados recolhidos.

\section{Preocupações Ambientais}

1. Indique, numa escala de 1 a 5 , a frequência com que pratica as ações mencionadas:

1-Nunca 2-Raramente 3-Às vezes 4-Frequentemente 5-Sempre

$\begin{array}{llllll} & 1 & 2 & 3 & 4 & 5 \\ \text { Efetua a separação dos resíduos domésticos (reciclagem). } & & 0 & 0 \\ \text { Enche sempre a máquina de lavar loiça e roupa antes de as por a funcionar. } & 0 & 0 & 0 & 0 \\ \text { Compra papel reciclado. } & 0 & 0 & 0 & 0 \\ \text { Reutiliza sacos de plástico. } & 0 & 0 & 0 & 0 & 0 \\ \text { Utiliza lâmpadas de baixo consumo. } & 0 & 0 & 0 & 0 & 0 \\ \text { Compra produtos com o rótulo ecológico. } & 0 & 0 & 0 & 0 & 0\end{array}$

\section{Reciclagem com Incentivo Económico}

2. Estaria disposto a reciclar sempre o plástico se a essa prática estivesse associada uma recompensa monetária? (Caso a sua resposta seja "Não" ou "Já reciclo sem recompensa", passe para a questão 5.)
S Sim
Não
Talvez
Já reciclo sem recompensa

3. Se o governo obrigasse as empresas de recolha seletiva a pagar 10 euros por $\mathrm{kg}$ de plástico que cada indivíduo reciclasse, concordaria com esta medida?

Sim

Não

4. Qual o valor em euros, que necessitaria de receber de modo a separar $1 \mathrm{~kg}$ de plástico?

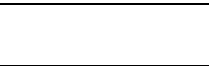

5. Estaria disposto a reciclar sempre o vidro se a essa prática estivesse associada uma recompensa monetária? (Caso a sua resposta seja "Não" ou "Já reciclo sem recompensa", passe para a questão 8 .)
O Sim
Não
Talvez
Já reciclo sem recompensa

6. Se o governo obrigasse as empresas de recolha seletiva a pagar 8 euros por $\mathrm{kg}$ de vidro que cada indivíduo reciclasse, concordaria com esta medida? 
Sim

Não

7. Qual o valor em euros, que necessitaria de receber de modo a separar $1 \mathrm{~kg}$ de vidro?

8. Estaria disposto a reciclar sempre o papel se a essa prática estivesse associada uma recompensa monetária? (Caso a sua resposta seja "Não" ou "Já reciclo sem recompensa", passe para a questão 11.)
O Sim
Não
Talvez
Já reciclo sem recompensa

9. Se o governo obrigasse as empresas de recolha seletiva a pagar 10 euros por $\mathrm{kg}$ de papel que cada indivíduo reciclasse, concordaria com esta medida?
O Sim
Não

10. Qual o valor em euros, que necessitaria de receber de modo a separar $1 \mathrm{~kg}$ de papel?

\section{Perfil do Inquirido}

11. Sexo:

Feminino

Masculino

12. Idade:

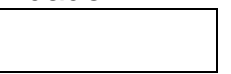

13. Habilitações académicas

Ensino Básico (Até ao $9^{\circ} \mathrm{ano}$ )

Ensino Secundário (Até ao $12^{\circ}$ ano)

Licenciatura/Bacharelato

Mestrado

A frequentar Licenciatura/Mestrado

Outro

14. Rendimento médio mensal (bruto)

Até $549 €$

Entre $550 €$ e $999 €$

Entre $1000 €$ e $1499 €$

Entre $1500 €$ e $2000 €$

Superior a $2000 €$

\section{Obrigada pela sua colaboração!}


Anexo III: Questionário n³ - Grupo Experimental da Âncora Baixa

\section{Reciclagem com Incentivo Económico}

O presente questionário surge no âmbito de uma dissertação de mestrado em Gestão da Escola Superior de Tecnologia e Gestão do Instituto Politécnico de Leiria. Agradeço a sua colaboração no preenchimento deste questionário (cerca de 2 minutos), que tem como objetivo reunir informação acerca da prática da reciclagem. É garantida a total confidencialidade e anonimato dos dados recolhidos.

\section{Preocupações Ambientais}

1. Indique, numa escala de 1 a 5 , a frequência com que pratica as ações mencionadas:

1-Nunca 2-Raramente 3-Às vezes 4-Frequentemente 5-Sempre

Efetua a separação dos resíduos domésticos (reciclagem).

Enche sempre a máquina de lavar loiça e roupa antes de as por a funcionar.

Compra papel reciclado.

Reutiliza sacos de plástico.

Utiliza lâmpadas de baixo consumo.

Compra produtos com o rótulo ecológico.

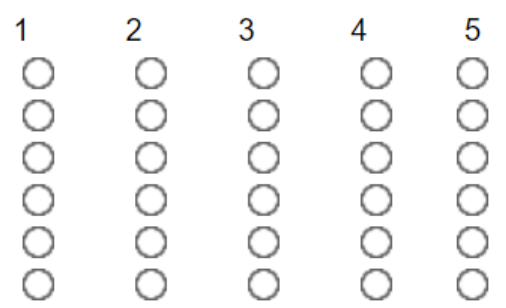

\section{Reciclagem com Incentivo Económico}

2. Estaria disposto a reciclar sempre o plástico se a essa prática estivesse associada uma recompensa monetária? (Caso a sua resposta seja "Não" ou "Já reciclo sem recompensa", passe para a questão 5.)
S Sim
Não
Talvez
Já reciclo sem recompensa

3. Se o governo obrigasse as empresas de recolha seletiva a pagar 80 cêntimos por $\mathrm{kg}$ de plástico que cada indivíduo reciclasse, concordaria com esta medida?
() Sim
Não

4. Qual o valor em euros, que necessitaria de receber de modo a separar $1 \mathrm{~kg}$ de plástico?

5. Estaria disposto a reciclar sempre o vidro se a essa prática estivesse associada uma recompensa monetária? (Caso a sua resposta seja "Não" ou "Já reciclo sem recompensa", passe para a questão 8.)
Sim
Não
Talvez
Já reciclo sem recompensa

6. Se o governo obrigasse as empresas de recolha seletiva a pagar 50 cêntimos por $\mathrm{kg}$ de vidro que cada indivíduo reciclasse, concordaria com esta medida?
O Sim
Não 
7. Qual o valor em euros, que necessitaria de receber de modo a separar $1 \mathrm{~kg}$ de vidro?

8. Estaria disposto a reciclar sempre o papel se a essa prática estivesse associada uma recompensa monetária? (Caso a sua resposta seja "Não" ou "Já reciclo sem recompensa", passe para a questão 11.)
O Sim
Não
Talvez
Já reciclo sem recompensa

9. Se o governo obrigasse as empresas de recolha seletiva a pagar 50 cêntimos por $\mathrm{kg}$ de papel que cada indivíduo reciclasse, concordaria com esta medida?

O Sim

Não

10. Qual o valor em euros, que necessitaria de receber de modo a separar $1 \mathrm{~kg}$ de papel?

\section{Perfil do Inquirido}

11. Sexo:

Feminino

Masculino

12. Idade:

13. Habilitações académicas

Ensino Básico (Até ao $9^{\circ} \mathrm{ano}$ )

Ensino Secundário (Até ao $12^{\circ}$ ano)

Licenciatura/Bacharelato

Mestrado

A frequentar Licenciatura/Mestrado

Outro

14. Rendimento médio mensal (bruto)

Até $549 €$

Entre $550 €$ e $999 €$

Entre $1000 €$ e $1499 €$

Entre $1500 €$ e $2000 €$

Superior a $2000 €$

\section{Obrigada pela sua colaboração!}

